DESIGNING PHOTOVOLTAIC SYSTEMS FOR ARCHITECTURAL INTEGRATION

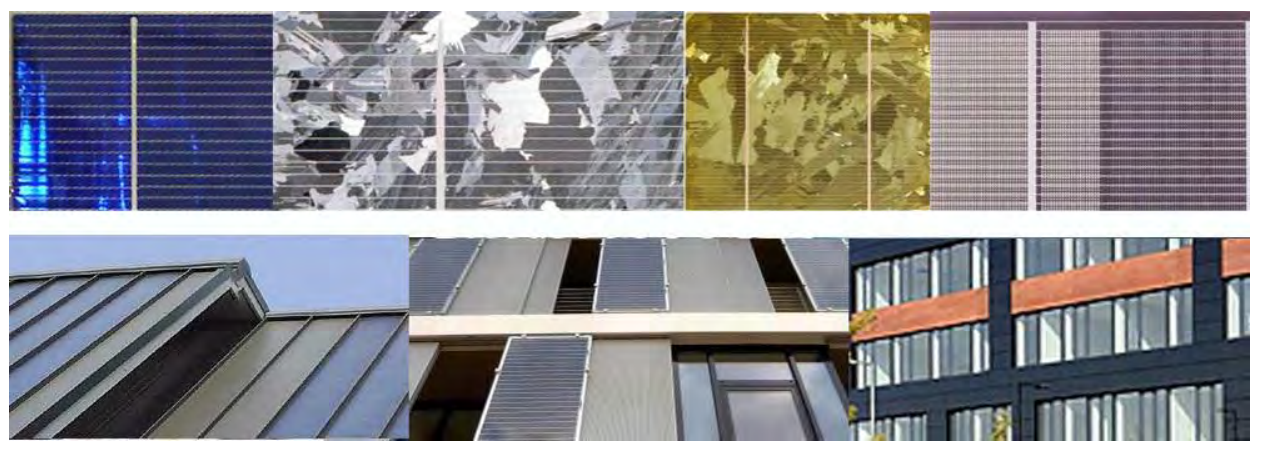

criteria and guidelines for product and system developers

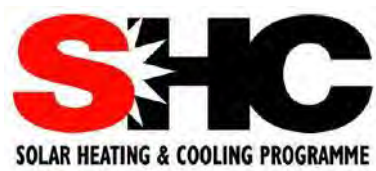

INTERNATIONAL ENERGY AGENCY 



\section{DESIGNING PHOTOVOLTAIC SYSTEMS FOR ARCHITECTURAL INTEGRATION}

Criteria and guidelines for product and system developers

\section{Keywords}

Solar energy, architectural integration, solar thermal, photovoltaics, active solar systems, solar buildings, solar architecture, solar products, innovative products, building integrability.

Editor Klaudia Farkas

August 2013

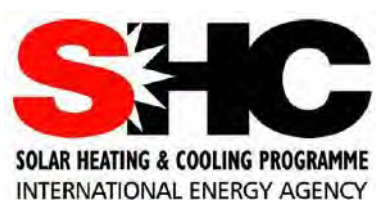





\section{AUTHORS AND CONTRIBUTORS AFFILIATIONS (IN ALPHABETICAL ORDER):}

Klaudia Farkas (editor, author)

Department of Architectural Design, History, and Technology

Norwegian University of Science and

Technology - NTNU

NO-7491 Trondheim

NORWAY

klaudia.farkas@ntnu.no

\section{Laura Maturi (author)}

EURAC research, Institute for

Renewable Energy

Universitá degli Studi di Trento

Viale Druso 1, I-39100 Bolzano, Italy

laura.maturi@eurac.edu

\section{Alessandra Scognamiglio}

(author)

ENEA (Italian National Agency for

New Technologies, Energy and

Sustainable Economic

Development) UTTP Portici

Piazzale E. Fermi 1

I-80055 Portici, NA

ITALY

alessandra.scognamiglio@enea.it
Francesco Frontini (author)

University of Applied Sciences and Arts

of Southern Switzerland (SUPSI)

Institute for Applied Sustainability to

the Built Environment (ISAAC)

Campus Trevano

$\mathrm{CH}-6952$ Canobbio

SWITZERLAND

francesco.frontini@supsi.ch

Maria Cristina Munari Probst (author)

EPFL-LESO

Bâtiment LE

Station 18

$\mathrm{CH}-1015$ Lausanne

SWITZERLAND

mariacristina.munariprobst@epfl.ch

Maria Wall (Operating agent,

contributor)

Energy and Building Design

Lund University

P.O. Box 118

SE-221 00 Lund

SWEDEN

maria.wall@ebd.Ith.se
Marja Lundgren (contributor)

White Arkitekter

P.O. Box 4700

Östgötagatan 100

SE-116 92 Stockholm

SWEDEN

marja.lundgren@white.se

Christian Roecker (author)

EPFL-LESO

Bâtiment LE

Station 18

$\mathrm{CH}-1015$ Lausanne

SWITZERLAND

christian.roecker@epfl.ch 



\section{ACKNOWLEDGMENTS}

The authors are grateful to the International Energy Agency for understanding the importance of this subject and accepting to initiate a task on solar energy and architecture. We wish to thank all our respective national Executive representatives and National funding bodies for funding this work, namely:

- Swiss Federal Office of Energy (OFEN)

- Ecole Polytechnique Fédérale de Lausanne (EPFL)

- Scuola Universitaria della Svizzera Italiana (SUPSI)

- Stiftung Südtiroler Sparkasse (Fondazione Cassa di Risparmio di Bolzano)

- European Academy of Bozen/Bolzano (EURAC)

- Universitá degli Studi di Trento

- ENEA - Agenzia nazionale per le nuove tecnologie, l'energia e lo sviluppo economico sostenibile

- SINTEF Building and Infrastructure, Norway

- Norwegian University of Science and Technology (NTNU)

- Swedish Energy Agency

- ARQ, body of two foundations established by White Arkitekter

- Arkus - Foundation for Research and Development in Archi tecture and the Built Environment

Finally, our gratitude goes to our helpful Operating Agent Maria Wall, and to Anne Grete Hestnes and Jens Windeleff for their initial crucial support to this task. 



\section{CONTENTS}

\section{ACKNOWLEDGMENTS}

EXECUTIVE SUMMARY

1. INTRODUCTION

2. ARCHITECTURAL INTEGRATION ISSUES AND SYSTEM DEVELOPMENT RECOMMENDATIONS 6

2.1 Definition of architectural integration 7

2.2 Functional and constructive development aspects $\quad 7$

2.3 Formal (aesthetics) development aspects 8

2.3.1 The architect's need of flexibility when working on

2.3.2 System characteristics affecting morphologycal integration quality 9

2.3.3 Concept of gradual levels of integration 9

2.4 Market trends/users preferences $\quad 11$

2.5 Production feasibility and eco-impact 11

3. PRACTICAL APPLICATION TO THE SPECIFIC PV SUBTECHNOLOGIES

3.1 Functional constructive development aspects $\quad 12$

3.1.1 Functional aspects (multifunctionality) 12

$\begin{array}{ll}3.1 .2 \text { Constructive aspects } & 15\end{array}$

3.1.3 Material compatibility 16

3.2 Formal development aspects 16

3.2.1 Crystalline modules $\quad 16$

$\begin{array}{ll}3.2 .2 \text { Thin film } & 21\end{array}$

4. DEVELOPMENT PROCESS EXAMPLES

4.1 The prototype of a new angle selective transparent BIPV façade component

4.1.1 Background and motivation $\quad 24$

4.1.2 Methodology (Extracted from [4.5]) 24

$\begin{array}{ll}\text { 4.1.3 Description of the BiPV system } & 27\end{array}$

4.1.4 Façade integration 28

4.2 The prototype of a wooden BIPV façade component $\quad 30$

$\begin{array}{ll}4.2 .1 \text { Concept } & 30\end{array}$

4.2.2 Description of the prototype 31

$\begin{array}{ll}\text { 4.2.3 Methodology } & 32\end{array}$

$\begin{array}{ll}\text { 4.2.4 Experimental campaign } & 32\end{array}$

5. EXAMPLES OF EXISTING PRODUCTS FOR BUILDING INTEGRATION 34

6. CONCLUSIONS

$\begin{array}{ll}\text { REFERENCES } & 77\end{array}$

ANNEX: IEA SOLAR HEATING AND COOLING PROGRAMME 80 



\section{EXECUTIVE SUMMARY}

Architects have mostly considered photovoltaics as merely technical devices, which has prevented their widespread use in buildings [0.1]. A variety of building dedicated PV products has been developed, as building integration came into focus. Still, architects are in general not satisfied with the products available on the market [0.2].

This document is targeted to product and system developers with the aim to present architectural issues related to building integration of photovoltaics. It provides a set of recommendations for product and system developers to meet the needs of architects for architectural integration of photovoltaics.

Chapter 1 gives a short introduction and is followed by general architectural integration issues in Chapter 2, covering functional, constructive and formal (aesthetics) development aspects. Chapter 2 also gives recommendations for system development by providing a concept for gradual integration levels:

- Basic level of integrability: ensuring module formal flexibility.

- Medium level of integrability: providing non-active elements.

- Advanced level of integrability: providing a complete roof/façade system.

Chapter 3 presents in detail the architectural integration issues applied to the specific PV sub-technologies (crystalline and thin film). Chapter 4 gives two examples of product development processes within real case studies. It describes the concept, the methodology, the BIPV system and the possible architectural integration of the specific product.

Chapter 5 consists of 21 datasheets of innovative PV products that were collected by the international experts of IEA SHC Task 41. Each datasheet presents a specific product with images and a short description. It also provides an evaluation of integration characteristics (multifunctionality, shape and size flexibility, pattern choice, colour choice, jointing/framing, availability of dummies, complete construction system), discussed in the previous chapters. The evaluation was done by the experts of Task 41.

The document ends with a short conclusion chapter. 


\section{INTRODUCTION}

In the last few years solar energy has been recognized in many countries as the most promising renewable energy for building application, so that photovoltaics are more and more installed on the building envelope. But most of the time, they look like added technical elements unrelated to the building context hosting them. The reason for this situation lies certainly in the fact that most systems at present are conceived and installed by energy specialists (electric engineers, installers), often not "designed" at all, without the implication of an architect. The result is a market offer in photovoltaics proposing standard products with a limited flexibility (in dimensions, texture, colour, jointing), and with very few products specially designed for architectural integration. This may be acceptable in the case of flat roof situations, but becomes more delicate for tilted roofs and clearly problematic when using façades.

This booklet is part of the effort of "IEA SHC Task 41 - Solar Energy and Architecture" to promote good quality solar architecture as a driving force for the diffusion of solar energy in buildings. It is intended to provide photovoltaic modules and component manufacturers with the information needed to make their products meet architectural integration requirements better.

The first part gives a clear definition of the building integration problematic, specifying all the functional, constructive, and formal (aesthetic) issues and the corresponding requirements. Special attention is given to the desired flexibility expected to ease the architectural integration process, like a broad offer in dimensions, textures, colours, the availability of dummies, etc. Even though all these wishes are not easily satisfied, the large size of photovoltaic systems at the roof or façade scale - especially for high solar fractions - strongly advocates considering them. The risk of not paying due attention to these issues is to discourage new users, or seeing, like it is happening in some countries, new building regulations limit the use of photovoltaics to hidden roofs, or even banning them from sensitive urban contexts. The second part gives practical recommendations for product development. Examples of possible ways to implement them in a development process are presented, highlighting required competences for each approach.

It may be worth noticing that to offer added formal flexibility these new products may have a slightly lower efficiency than standard products. As they allow installing systems in areas for which standard products are not suited or would not be accepted, the compromise makes sense: a slightly less efficient system installed is certainly better than a super-efficient one not installed! Examples of such innovative products specially developed for building integration are given at the end of the booklet. 


\section{ARCHITECTURAL INTEGRATION ISSUES AND SYSTEM DEVELOPMENT RECOMMENDATIONS}

Most existing photovoltaic modules are developed as purely technical elements, starting from the "energy production" point of view only, by sizing the modules to optimize energy collection, manufacturability, handling, and installation, but only giving a marginal attention to architectural integration issues. A typical development process would see an industrial designer just bring the last touch to the design, improving its look, not its "integrability".

PV modules must be developed to respond to their own technical constraints but should furthermore become architectural elements, easy to integrate into the building envelope. They should possibly fulfil more than one function, consequently supporting designers' integration efforts and reducing the overall cost [2.1;2.2].

Few main characteristics distinguish the various active solar technologies, determining their integration possibilities:

- $\quad$ the medium used for the energy transportation (electricity, air, water...);

- the materials composing the module (mono-poly crystalline silicon, plastic, metal, glass...);

- $\quad$ the intrinsic form of the module (PV module, flat plate, multilayer flat plates, tubes...).

These characteristics have a major impact on the architectural integration possibilities at all levels: functional, constructive, and formal.

New designs should explore the possibilities that are compatible with the collector's functioning to meet also building integration requirements, users' expectations and production constraints (manufacturability, standardization, costs...).

As written above, it should be kept in mind that as these new collectors will be more "building-oriented" there might be unavoidable trade-offs on efficiency or cost to accept, but these should be compensated by a broader acceptance and better implementation possibilities. This means also that there is now room for a new palette of module types with a clear "building function", each addressed to a specific building application, such as metallic cladding, glazed façade element, balcony fence, tilted roof shingle, etc. 
Taking this approach implies both to follow a new module development procedure and to redefine the main purpose of the PV component, different from the traditional one, whose prerequisite is the appropriate composition of the design team. For the development of these multifunctional construction elements, the design team should have competences in the fields of solar energy production, architecture and building technology.

\subsection{DEFINITION OF ARCHITECTURAL INTEGRATION}

The architectural "integrability" of solar modules should be considered at the three basic architectural levels: functional, constructive, and formal. Relevant possibilities and constraints in relation to these three different aspects of the integration are described in the coming sections, considering the specificities of the different technologies.

\subsection{FUNCTIONAL AND CONSTRUCTIVE DEVELOPMENT ASPECTS}

The need for a functional/constructive integration of active solar elements in the building envelope has been theorized by several researchers. The main stressed advantages are the reduction of the overall cost and the smaller architectural integration effort they bring.

Integrating solar modules in the building envelope means to integrate the energy collection function (active production of solar energy) while preserving/ensuring the other envelope functions. A good knowledge of the latest is therefore fundamental to understand which parts PV modules could replace. However, PV modules are not only used in envelopes (separation of inside/outside) but can also be used in external separation elements, like balconies, or in external equipment, like canopies.

Building envelopes have the following main protection and regulation functions:

- Protection from intrusion, rain, wind and noise;

- Insulation from winter cold and excessive summer heat (weather protection);

- Regulation of the visual relations inside/outside and outside/inside, as well as the supply of fresh air, daylight, and passive solar gains;

- Regulation of users' comfort, while reducing the use of non-renewable energies for heating, cooling and lighting to the minimum (thermal protection).

To comply with these needs, the envelope is articulated into different opaque and transparent parts, composed by fixed and/or mobile elements, each of them fulfilling a specific set of functions[2.3;2.4;2.5].

The opaque parts fulfil mainly protection functions (from intrusions, rain, wind, noise, heat, cold...). In buildings responding to the new energy standards, opaque parts are mainly composed of multilayer systems. The optimization of the protection from heat and cold function makes it a common practice to use an external insulation layer, as 
this helps avoiding important thermal bridges and related condensation problems. This practice requires the use of an external protection (cladding).

The opaque envelope parts are mainly composed of fixed elements (with the exception of doors and - rarely - opaque ventilation elements).

The transparent (or translucent) parts are meant to collect daylight and passive solar thermal gains, to provide the visual contact with the outdoor, while still ensuring the whole set of protection functions. Transparent parts are mainly composed of mobile components and systems, to regulate daylighting, passive solar gains, the visual inside/outside relation, and in most cases also the natural ventilation.

Integrating a new component for "solar collection" into the building envelope requires understanding where (opaque parts, transparent parts, fixed/mobile elements) and how this added element can be made compatible with the other envelope parts, materials and functions.

The compatibility level will be different depending on the characteristics of the selected solar technology and the characteristics of the specific envelope element chosen. In any case, the new multifunctional envelope system has to meet safely all the related standard building construction requirements [see section 2.1]:

- The module load should be correctly transferred to the load bearing structure through appropriate fixing;

- The fixing should avoid thermal bridges and the global U-value of the wall should not be negatively affected;

- The module should withstand fire, weather wear, and tear;

- The module should resist wind loads and impacts, and should be safe in case of damage.

Dedicated chapters will detail the specificities of various photovoltaic technologies and their main implications for the module developments.

\subsection{FORMAL (AESTHETICS) DEVELOPMENT ASPECTS}

\subsubsection{THE ARCHITECT'S NEED OF FLEXIBILITY WHEN WORKING ON BUILDING INTEGRATION}

In this context, the word "formal" refers to the appearance of elements. It is used where common practice would use "aesthetical", or "architectural", as it is more accurate. Moreover, this avoids confusion with the broader meaning of "architectural integration".

To successfully develop products helping architects integrate solar systems, it is crucial to understand the formal (aesthetic) criteria that command the quality of integration: functional and constructive integration criteria can be easily described; formal criteria 
are more problematic, as often perceived as subjective. But as demonstrated by a survey conducted in 2004 among a large group of EU architects and engineers, objective criteria do exist in this field [2.6].

The survey demonstrated two important points in evaluating formal integration quality:

- Architects' judgments were consistent with each other, confirming the existence of general criteria used as common judgment base

- Engineers' and façade manufacturers' judgments were more dispersed and, more importantly, always less demanding regarding integration quality

These differences in appreciation confirmed that judging architectural quality relies on architects' professional competences, showing the importance of using architects' skills when dealing with formal issues.

\subsubsection{SYSTEM CHARACTERISTICS AFFECTING MORPHOLOGICAL INTEGRATION QUALITY}

The survey results underlined that all system characteristics affecting building appearance (i.e. all formal characteristics) have an impact on integration quality.

These characteristics can be summarized as follows:

1. Size and position of module field

2. Module material and surface texture

3. Absorber colour

4. Module size and shape

5. Type of jointing

For a completely successful integration, all these characteristics should be coherent with the overall building design logic. Consequently, the more flexibility offered by a product for each characteristic, the easier the integration work for the architect.

\subsubsection{CONCEPT OF GRADUAL LEVELS OF INTEGRATION}

Three progressive levels of integrability can be defined: basic, medium and advanced (see Fig.2.1 1). This should help producers improve their offer in progressive steps.

Basic level of integrability: ensure formal flexibility of the module.

In order to be adaptive to specific contexts and buildings (both new and retrofits), solar systems should be able to provide flexibility on a maximum of module characteristics affecting building appearance:

- Module shape and size should offer a maximum dimensional freedom to cope with the great variability of building dimensional constraints.

- Offering an appropriate selection of jointing is an added means to interact correctly with the building envelope. 
- A reasonable palette of collector colours and surface-finishing improves interfacing collectors with other colours and surface textures of the building.

Medium level of "integrability": provide non-active elements.

The next integration step is to offer non-active elements, similar to the modules, but fulfilling only the added envelope function; they will help position and dimension the whole system field according to building composition needs. These elements are called "dummies", even though this word is slightly misleading in the case of the multifunctional module, since the non-active element still fulfils a real function (e.g. the cladding).

Advanced level of integrability: provide a complete roof/façade system.

The maximum integrability is reached when a complete active envelope system is offered by providing also all the needed complementary interface elements (jointing/finishing/angular components).

To develop such integral solar roof/façade systems, two approaches can be considered:

1. Start from the module and complete the system by designing all the interface elements around it. This path gives the maximum freedom to designers and might offer some additional functionality to the non-active elements, but at the extensive cost of developing a whole roof/façade concept.

\section{Start from the roof/façade system}

This approach means to adapt the new multifunctional module to an already existing roof/façade system.

This option may require some modifications to the module's initial design and to the original roof/façade system (piping/cabling transfer, colour on demand), but in most cases it will be quicker to develop and more cost effective, with the additional benefit of offering access to an existing market.

This approach was recently taken by the façade and roof manufacturer Rheinzink to develop its latest Solar PV Standing Steam and Click Roll Cap roof systems. They use flexible Unisolar thin film laminates for their systems conceived to be compatible with the already existing Rheinzink Standing Steam and Click Roll Cap roof covering system (see Section 5, Innovative products). Another recent development was by the curtain wall manufacturer Schüco that integrated opaque and translucent PV thin film into their glazing. The opaque panels are used in ventilated cladding (SCC 60, see Section 5.2 Innovative products,) and the translucent ones in thermal insulated glass of windows and curtain wall façades (ProSol TF, see Section 5, Innovative products). 


\subsection{MARKET TRENDS/USERS PREFERENCES}

To ensure that the new collector will have a market, the desired level of freedom and the aesthetic preferences of the potential users have to be investigated. Existing market analysis and/or specific surveys can be used for this purpose.

Knowing users' expectations helps decide which compromises can be made and which ones should be avoided regarding the level of formal flexibility offered by the new product.

\subsection{PRODUCTION FEASIBILITY AND ECO-IMPACT}

Manufacturability and production cost of PV modules and associated system elements also need to be considered. In this analysis, the overall construction cost reduction resulting from the multifunctional use of the collector should be taken into account. $A$ key challenge lies in the careful balancing of standardization needs and user's desired freedom.

As for the economic cost, the energy cost of the multifunctional system should also be evaluated. The embodied energy required for the production-distribution-mountingdismounting of the system should be considered. The global eco-impact of the system should then be evaluated in the light of the energy savings resulting from the solar energy production and also from the merging of several envelope functions in one element. This point is especially important considering the global goal of solar technologies and the ecological sensitivity of target customers.

The Fig.2.1 hereafter summarizes the whole development approach. 


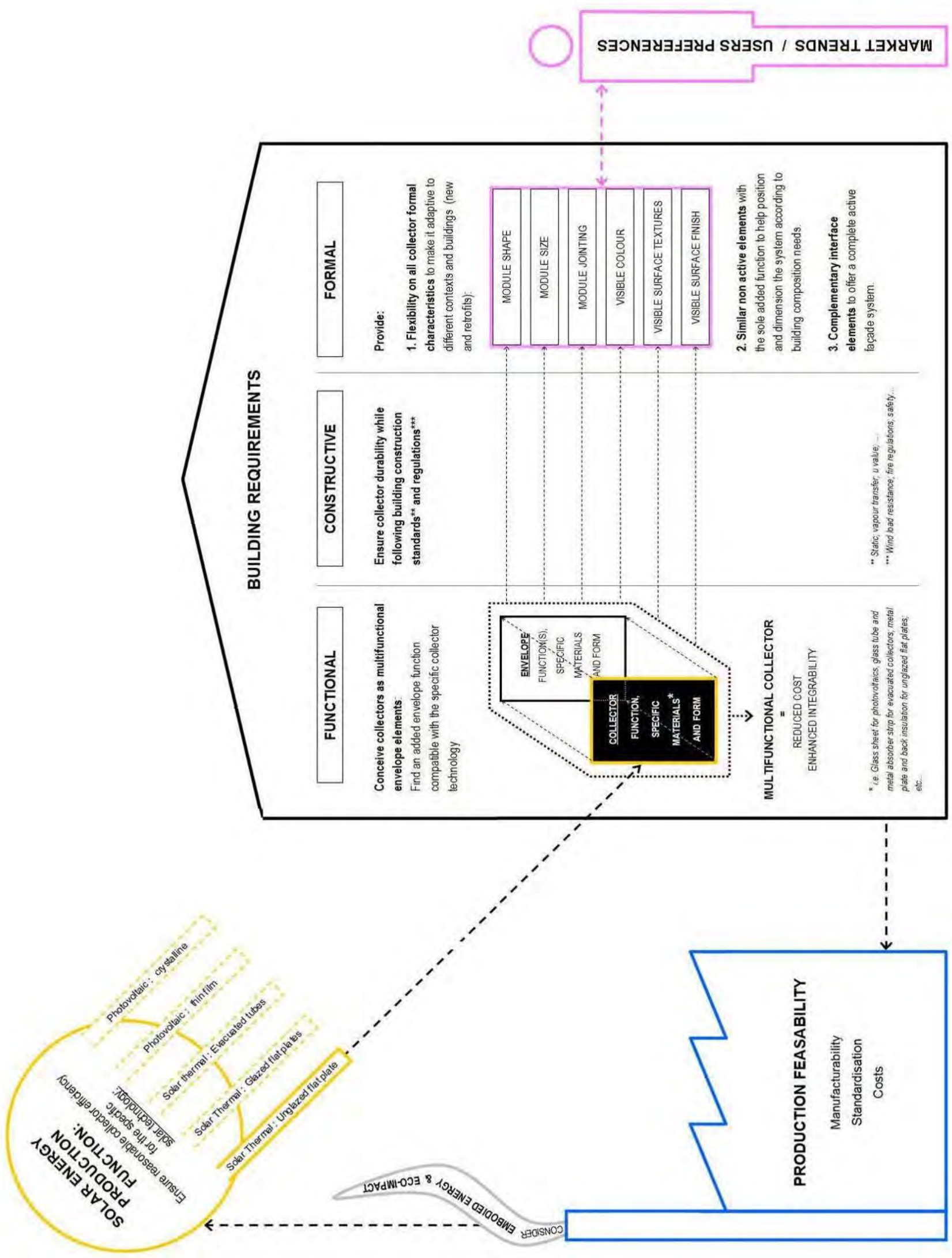

Fig.2.1.: Global development process for multifunctional building systems. 


\section{PRACTICAL APPLICATION TO THE SPECIFIC PV SUBTECHNOLOGIES}

\subsection{FUNCTIONAL CONSTRUCTIVE DEVELOPMENT ASPECTS}

\subsubsection{FUNCTIONAL ASPECTS (MULTIFUNCTIONALITY)}

As we already pointed out, there are two basic ways of using PV in buildings: one is by adding PV on the envelope (BAPV-Building Added Photovoltaics), the other is by substituting parts of the building envelope using PV (BIPV-Building Integrated Photovoltaics).

In the case of BAPV, if we look at the appropriate PV products to utilize, standard PV modules can be normally used and added on buildings by means of a suited mounting system. The PV modules have no special requirements to meet in addition to the standard ones, since they do not perform any additional building function.

On the contrary, a photovoltaic module which is used in the substitution of traditional elements of the building envelope (BIPV) has to ensure all the functions of the replaced element. It means that a BIPV module has to meet requirements that a standard PV module does not need to meet (i.e.: thermal and mechanical resistance). This is a crucial and very important point, especially nowadays because up to now a standard "dedicated to building integration" PV module does not exist. For this reason, if we want to integrate a PV module in a building, we have both to comply with the electrotechnical requirements as stated in the low voltage directive $2006 / 95 /$ IEC or CENELEC standards, related to the module itself, and with the building products standards as provided by the European construction product directive CPD 89/106/EEC. But if IEC standards are guaranteed by the PV module manufacturer and are listed in the module's datasheet, the building requirements are still not integrated in the standard module certification and marking.

To harmonize the standards, in 2010, CENELEC (European Committee for Electrotechnical Standardization) started the project "prEN 50583: Photovoltaics in buildings" (CLC/TC 82 Scope), based on the Technical Committee for Electrotechnical Standardization, and whose aim is "to prepare European Standards for systems and components for photovoltaic conversion of solar energy into electrical energy and for all elements in the entire photovoltaic energy system" (for further information see [3.1] and [3.12]). This new standard should help both manufacturers and architects or planners to easily use PV modules as building elements. Thermal and optical 
characteristics together with structural resistance are important information that architects and designers need for implementing PV modules in their common design.

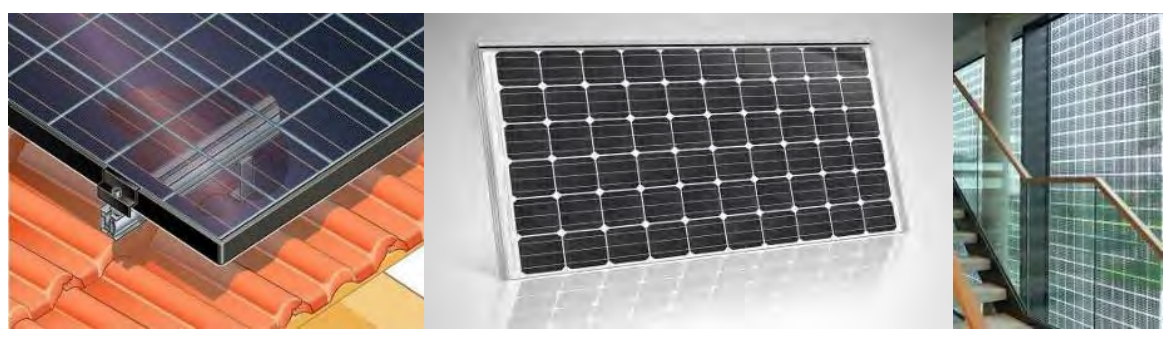

Fig 3.1: from left to right / BAPV mounting system Intersol @) Intersol / BIPV special component for roofs Silfab4Roof (based on Solrif patent) @ C Silfab / BIPV special photovoltaic module for semi-transparent façade (glass-glass module) @ Sunways

Generally, the "building" function can be ensured either by a special photovoltaic component that performs as a system, made of the PV module + the mounting system, or by a special photovoltaic module. Typical examples for the first family of products are the PV systems for replacing roofs or façades, while those for the second family are the glass-glass modules for replacing glazed surfaces of building envelopes (Fig 3.1).

With regard to the main PV technologies, crystalline and thin films, apart from the standard PV modules (which do not have the right specifications to be used in the substitution of building envelope elements), the basic families of products are presented in Table 1.

Table 1: Basic product families of photovoltaic modules substituting other building components

\begin{tabular}{|c|c|c|c|}
\hline \multirow{2}{*}{$\begin{array}{l}\text { Crystalline } \\
\text { (rigid) }\end{array}$} & Special modules & Glass-glass modules & $\begin{array}{l}\text { Suitable to substitute parts } \\
\text { of glazed envelopes }\end{array}$ \\
\hline & Special components & $\begin{array}{l}\text { Frameless modules } \\
\text { equipped with a mounting } \\
\text { system that ensures the } \\
\text { technological integrability }\end{array}$ & $\begin{array}{l}\text { Suitable to substitute roofs } \\
\text { or façades (generally } \\
\text { opaque) }\end{array}$ \\
\hline \multirow[t]{3}{*}{ Thin films } & Special modules & Glass-glass modules & $\begin{array}{l}\text { Suitable to substitute parts } \\
\text { of glazed envelopes or } \\
\text { cladding element }\end{array}$ \\
\hline & $\begin{array}{l}\text { Semi-industrialized } \\
\text { laminates to integrate in } \\
\text { building elements }\end{array}$ & Steel sheets & $\begin{array}{l}\text { Generally used as roofs of } \\
\text { industrial buildings (no } \\
\text { special thermal } \\
\text { requirements), or as part of } \\
\text { prefabricated building } \\
\text { systems, where they are the } \\
\text { external layer }\end{array}$ \\
\hline & & Membranes & $\begin{array}{l}\text { Generally used to replace the } \\
\text { roof membrane (water } \\
\text { tightness) }\end{array}$ \\
\hline
\end{tabular}

Although PV modules are generally impermeable, the most difficult part is the water tightness of the whole system, since by using PV modules the number of jointing is increased, with a consequent risk for the water tightness. In this case, the problem is 
not the PV module itself, but the PV system (module + mounting system) as a whole, meaning a special attention is needed when mounting the system, especially for roof integrated PV systems. The approach for the development of PV products should be similar to the case of the traditional building industry.

Using PV components can possibly improve the bioclimatic control capability of the envelope. The use of PV as a second skin can help in re-using the heat dissipated by the modules to improve the interior thermal comfort.

The addition of PV elements to the building envelope, or in external equipment systems, can be very useful in the control of the thermal radiation (i.e. canopies on façade, solar greenhouses etc). Also the use of semitransparent PV modules as elements of the façade can help in the daylight control as well as in reducing the thermal load for the interior comfort.

In order to understand how to choose the appropriate PV product for a given application, it is important to list the requirements that the component has to meet. To do this, the easiest way is to divide the envelope in technological units: closing units that divide the interior from the exterior (e.g. glazing); separation units that divide or give form to external spaces (e.g. balustrades); external equipment that allow the use of external spaces related to the building (e.g. canopies).

PV can be used in relation to one of these technological units of the building system; the main criterion for selecting the right PV product is the integration degree of the component; in particular, depending on the layer of the technological unit layering the PV substitute, it is possible to list its requirements. For example: in the case of a tiled roof, a special PV component does not substitute the whole closing unit (roof), but only the external layer of this unit, the tiles. As a consequence, the PV product has to perform the same functions as the tiles: thermal and mechanical resistance, water and air tightness, and fire safety.

In the use of PV components or modules for buildings, the higher the industrialization grade, the higher the affordability. For the designer, it is in fact very important to handle a product that is certified and described in a comprehensive datasheet listing all the product features: in addition to the electric characteristics, the thermal, mechanical and optical ones. See detailed requirements in section 2.2. Functional and constructive development aspects.

\subsubsection{CONSTRUCTIVE ASPECTS}

The PV systems have to integrate in terms of dimensions and functions with the preexisting technical elements. They have to ease the interfacing with the traditional building elements, not reducing their performances but, possibly, improving them. In the particular case of envelope elements (roofs and façades), the PV systems have to 
ensure the water tightness of the whole system, and the impermeability of the exposed surfaces.

For the static compatibility of PV modules and components, the traditional mechanical resistance requirements have to be met. In this case, the whole system composed of the PV module and the mounting elements has to meet the appropriate requirements. Apart from the mechanical resistance, these requirements depend on the application type. For example, for the roofs: snow and wind loads, and the weight of people who can step on the roof for maintenance needs. The wind load is particularly important in all the cases where PV modules are added on the building envelope, since the modules are linked to the supporting structure only by means of punctual elements. See detailed requirements in section 2.2. Functional and constructive development aspects.

\subsubsection{MATERIAL COMPATIBILITY}

There are at least two aspects to take into account the compatibility between PV and the existing materials of the building: One is the different thermal expansion coefficients of the materials, while the other is the risk of galvanic corrosion. These problems are not different from cases where only traditional materials are used and there are no specific indications for PV.

\subsection{FORMAL DEVELOPMENT ASPECTS}

\subsubsection{CRYSTALLINE MODULES}

\section{a. Module shape and size}

In general, architects require a high flexibility in shape and size of crystalline modules in order to have a large freedom to integrate them into the architectural design [3.2]. That means to have a wide palette of shape and size provided by the manufacturer. On the other hand, among building dedicated products (that are products specifically designed for building integration), there are different requirements for different types of products [3.3]:

Products developed to match and replace existing building products Certain BIPV products are specifically developed to replace and to be compatible with existing products and their mounting system (most commonly for roof systems like tiles, shingles etc. (Fig 3.2) [3.4]. The shape and size of these products have to follow the original product. The shape and size of the cells are a limiting factor to follow any free form. However, recently very innovative solar tiles appeared in the market, cutting the cells into thin slices to follow the curved form of traditional tiles (Fig 3.2). 


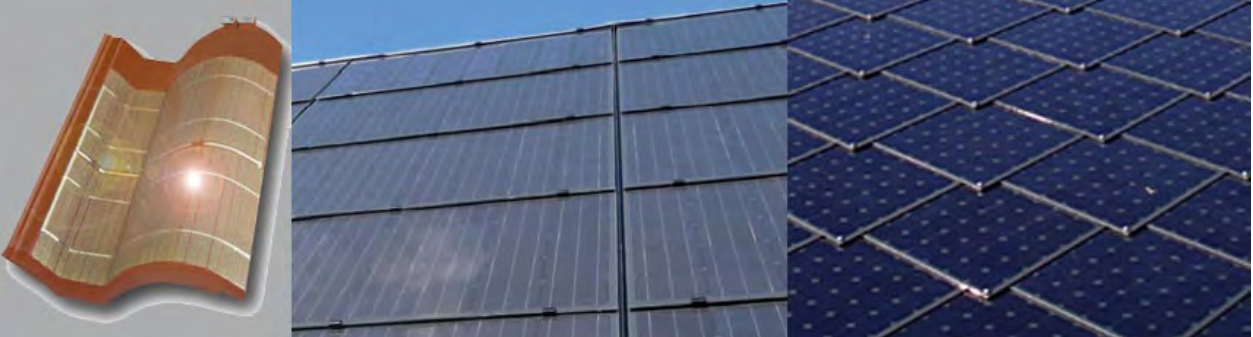

Fig 3.2: From left to right: Solar tile @ Ideassolar, Solar slate () Megaslate, Solar slate @ Sunstyle Solaire France

\section{Complete PV systems developed for building integration}

Complete product systems that include PV modules provide also mounting and interface components. When the modules are developed into an existing roof, façade or shading product system, the shape and size of the modules should match the shape and size of the original components (Fig 3.3). In case the product system with all the interface elements is designed to match a specific PV module (Fig 3.3-right), the manufacturer should provide a palette of products' shape and size, as well as dummies for specific details (corners, edges).
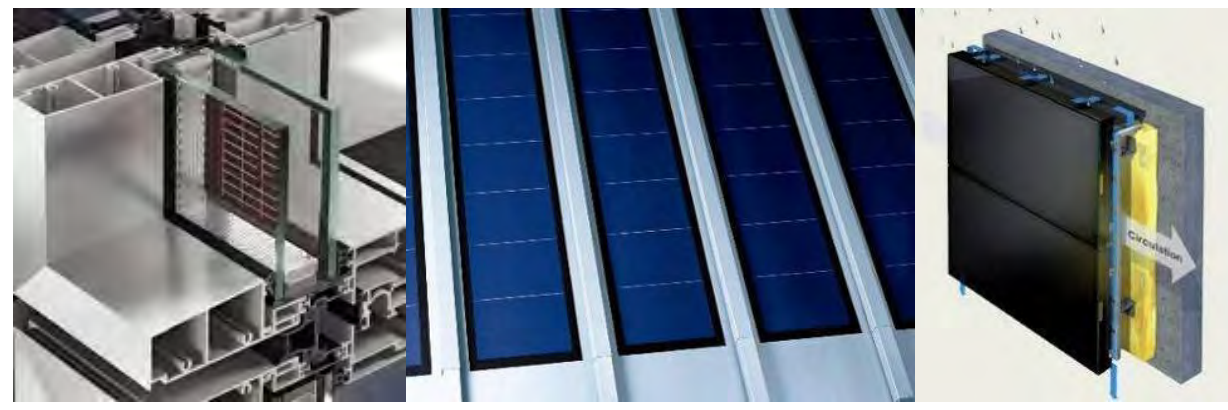

Fig 3.3: From left to right: Schueco ProSol translucent glazing @ Schueco, Metal cladding @ Rheinzink, Façade cladding (C) Soltecture

\section{Custom-made products developed for special projects}

Custom-made products can provide the highest flexibility of shape and size that architects need. However the extra costs of these products are important and spare parts should be produced together with the original ones to ensure replacement in case of damage.

\section{Dummies}

Regarding shape and size, in most projects where PV modules are integrated into the building skin, there is a need for specific elements with special dimensions and shape (by edges, corners...), that cannot be fulfilled with the PV modules provided by manufacturers. Furthermore, certain parts of the building skin are not suitable for energy production (shading or not exposed to the sun), but the architectural design might require to use PV components on these surfaces. In these two cases there is a possibility to use dummy (fake) elements that have the same formal characteristics (colour, texture, pattern, finishing material) as the PV component, but they do not 
produce electricity. Manufacturers should provide dummies with flexible shapes and sizes.

\section{b. Module/cell colour, pattern, texture, visible materials}

In most cases, PV cells are in the dark, cold range of colours (black, blue, purple, green), as opposed to most building surfaces that are generally in the light, warm range of colours, typically found in building materials (plasters, stones, bricks).

A smaller number of producers now offer a variety of colourful cells achieved with antireflection layers (Fig 3.4 and Fig 3.5). Since they have lower efficiency and higher costs at the moment they are not so much produced by the PV industry, but are more common in custom-made products. The architects wanted more freedom in choosing colours, but the most popular colour is still different shades of grey [3.5].

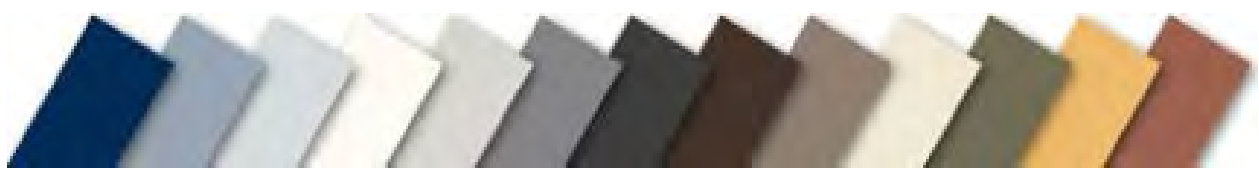

Fig 3.4: Colour palette for monocrystalline cells, (C) System Photonics

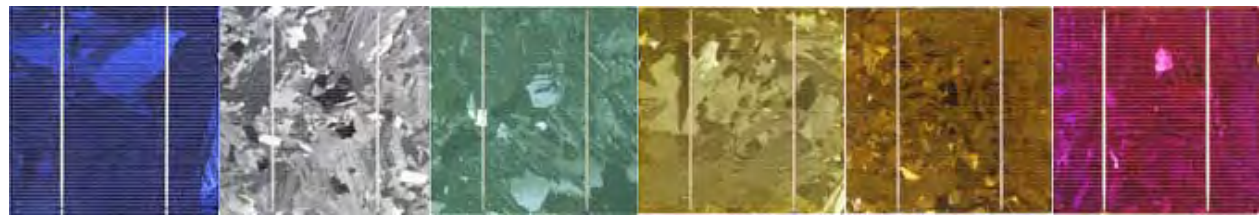

Fig 3.5: Multicrystalline silicon wafers; first the blue antireflective standard colour with the best efficiency, the second is the original wafer without reflective layer, then cells with other colours that have different antireflective layers, (C) Sunways

Through the pixelling effect, the pattern of crystalline modules can vary a lot either by placing the cells with a certain gap between them in semi-transparent modules, or by using differently coloured cells in a given pattern (Fig 3.6) [3.6].

So far there have been two limitations:

- extra cost of custom-made modules

- $\quad$ strict quadratic grid of arranging the cells
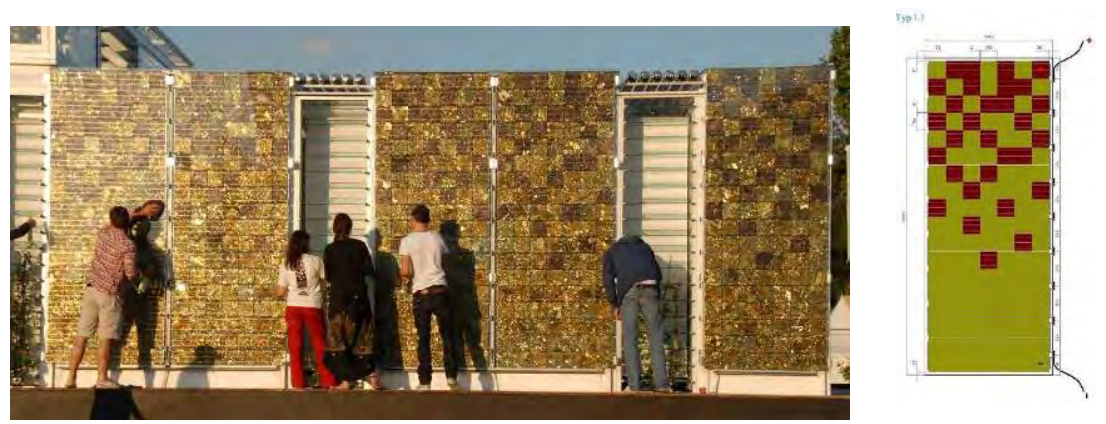

Fig 3.6: home + pavilion for Solar Decathlon, photo of façade and technical drawing of a façade module, (C) Prof. Dr. Jan Cremers 
The architects were also asking for a higher degree of flexibility in choosing the level of transparency and more options of texture [3.2]. For semi-transparent modules there should be a variety of mass produced modules with different standardized patterns (Fig 3.7) and there is also a need for advice on what can be used in which situation (e.g. windows for offices, curtain wall glazing for large entrance halls...etc.).
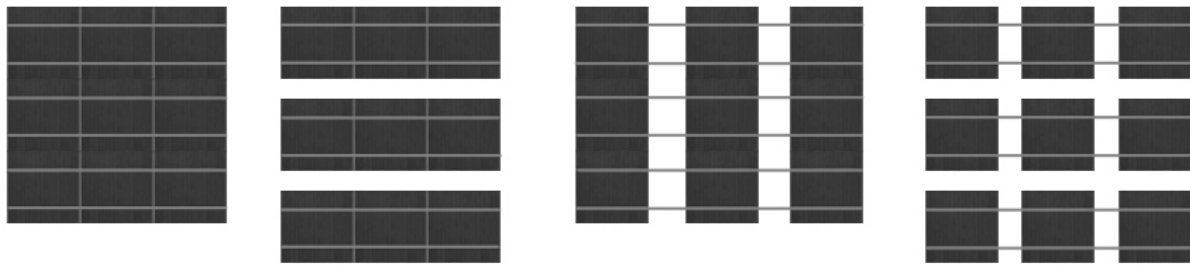

Fig 3.7: Different basic patterns of solar cells, (c) K. Farkas

The features of the pattern, such as the daylighting effect, visual contact with the outdoor environment, shading effect or heating of the backside, may be studied [3.7], such as reported in "Visual studies of transparent PV-element" (Fig 3.8) [3.8] or by studying existing projects .
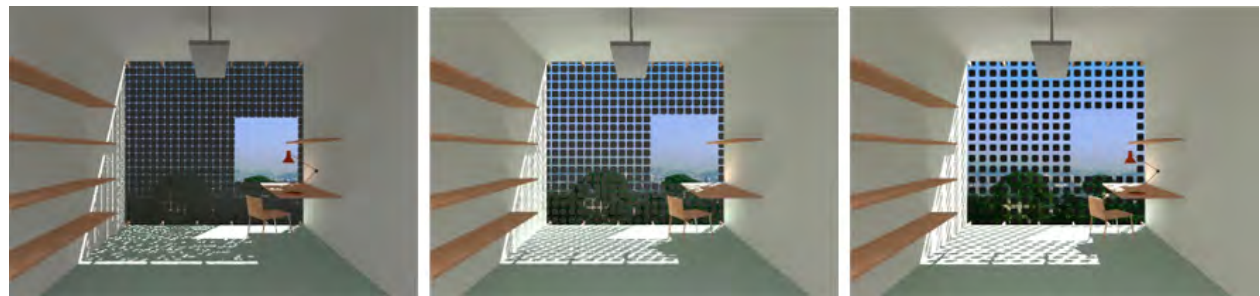

Fig 3.8: Visual studies of different cell patterns, (C) A.G. Lien
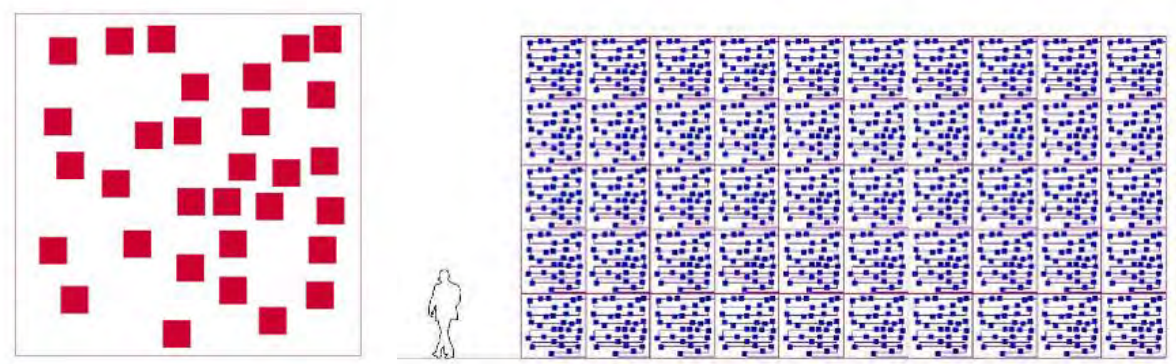

Fig 3.7: left: scheme of random pixellated photovoltaic module (Boogie Woogie) / 2005 / ENEA patent, design A. Scognamiglio / right: scheme of a façade using random pixellated modules Boogie Woogie (C) A. Scognamiglio [3.9]

Recent research on architectural integration of photovoltaic cells highlighted that it is not necessary to keep a strict quadratic grid of the PV cells, but for the easier manufacturing process it is important to keep the electric wiring straight and parallel [3.10]. That means that in one dimension the straight lines of the wiring has to be followed, but in the other dimension the cells are free to slide (Fig 3.8) [3.11]. This process opens up an even wider freedom in designing PV patterns with even curved lines. 

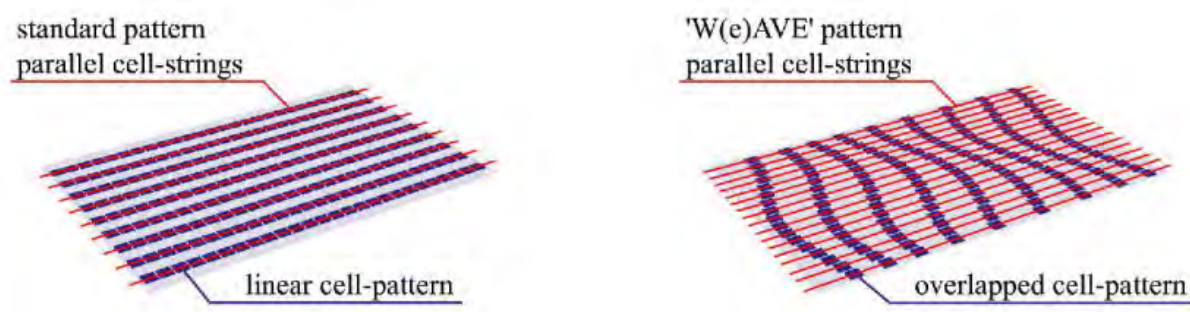

Fig 3.8: 'W(e)AVE pattern with parallel cell-strings, (C) R. Baum

The texture of the cell is given by the technology. However, by cutting out different patterns of the cells or by using different wiring patterns (Fig 3.9), the texture can vary a lot.
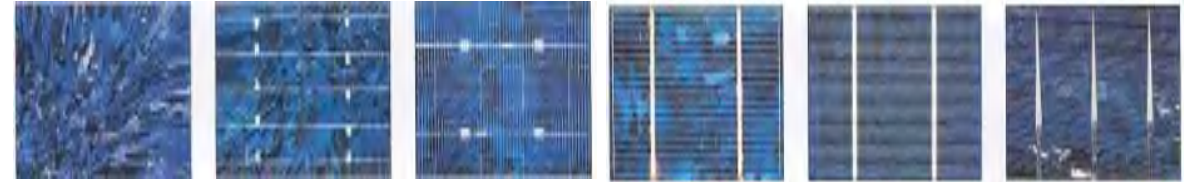

Fig 3.9: Different variations of the metallic grid pattern on multicrystalline cells, CC IEA-PVPS Task7

There is also a need to be able to select different textured or etched extra-white front glass materials, while providing the information of efficiency compared to modules with standard front glass.

Regarding the materials used to encapsulate the cells, there have been two comments by architects [3.2]:

- in case the front material is glass, the products should be compatible with other glass constructions like curtain walls and so become part of a new glass architecture

- use another material than glass, like plastic, for more flexibility, bendability, and less reflectivity

PV surfaces are always smooth and polished, while the building surfaces very often are characterized by a wide variety of grain. The matching between the two different surfaces implies two opposite couples: reflecting/absorbing with regard to the surface reflectivity and polish/rough with regard to the roughness of materials. To smooth the grain variation, PV components with "rough" external surfaces could be developed. The building texture is much richer than the texture of PV modules and components. In fact, in the first case, the texture depends on the materials as well as on the wide surface composition, while in the second case, the texture is basically set by the dimensions of the PV modules.

To smooth the texture variation, it is important to develop PV products that match the dimension of the building materials. Sometimes this turned out to be not very convenient (see PV tiles, too small to be efficient and cost effective), so a good 
approach could be using the modularity of some building elements to design PV components.

\section{c. Jointing}

The type of jointing and its flexibility also depends on the type of product. Once the product is part of an existing product system, the jointing solutions are already provided by the product system. In other cases there is a need from the architects to select from different possibilities regarding the visual appearance:

- frameless modules

- framing encapsulated in the glazing

- framing covering the edges of modules (cautions should be made for the shading of cells by the framing)

In case there is a framing, there should be a palette of dimensions (different widths) and colours offered by the manufacturer.

\subsubsection{THIN FILM MODULES}

Since glass-glass modules and thin film laminates have different formal characteristics and already have different formal flexibility, there are different needs in their product development.

\section{a. Module shape and size}

The three types of products discussed for crystalline modules are also relevant for thin film products. The shape and size of products that are replacing existing building products (like tiles) should follow the shape and size of the original product. The complete system that incorporates PV products should provide a set of dimensions to choose from as well as dummy elements for special needs.

Thin film laminates currently have a limitation as the widths are fixed and that there is only certain flexibility in lengths. The most important advantage compared to the other PV modules is the bendability of the laminates that makes them suitable for curved surfaces. Hence, these products are particularly suitable to integrate into metal roof/façade claddings and flat roofs although there still is a need for a palette of different widths for further applications.

\section{b. Module/cell colour, pattern, texture, visible materials}

Most manufacturers provide basic thin film modules with one particular colour like brown, blue or black and laminates in dark blue or magenta. The colour choice is still limited to a few manufacturers (Fig 3.10) and thus there is a need to develop more options as well as a wider palette of colours for selection. 

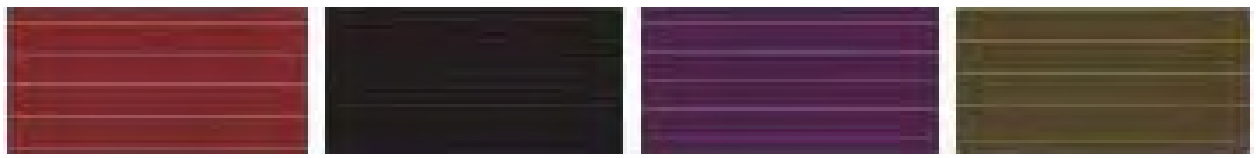

Fig 3.10: Coloured thin film modules in reddish brown, chocolate-brown, hepatic and sage green colour, (C) Rixin

Laser cutting opened the possibility to produce translucent panels with different patterns. There is already a set of different products with different textures available in the market. One of the requests of architects was if PV could be used as painting in order to design any free pattern by using photovoltaics [3.2]. That means that architects asked to have the possibility to laser cut their own custom-made image without too much extra cost. Another requirement is to have useful data of the mass produced translucent modules, regarding efficiency (compared to opaque modules) and daylighting issues.

Thin film laminates currently have a particular surface texture and two empty lateral areas where the substrate is visible. The possibility of selecting the colour and dimensions of the substrate would provide higher flexibility for architects.

\section{c. Jointing}

Regarding glass-glass modules, the requirements for framing possibilities are the same as for crystalline modules.

In case of thin film laminates, the jointing depends on the substrate structure. For example, if the laminate is integrated into an existing product system, the jointing solutions are given by the original product. In other cases, there is a need for a set of solutions to choose from with different jointing solutions for higher flexibility. 


\section{DEVELOPMENT PROCESS EXAMPLES}

This section presents the development and the optimization process of two different BIPV prototypes. Both examples are PV-façade components which not only produce electricity but also are able to fulfil other building requirements. This is why it is called "multifunctionality" in the text.

The first prototype is a multifunctional semi-transparent PV module conceived for building integration, which combines in one element several tasks such as providing solar and glare protection, allowing visual contact with outside and producing electricity.

The second example is a multifunctional opaque PV-façade system conceived as a prefabricated building component able to provide thermal insulation, climate protection and electricity production. For this prototype, a technological solution was developed to integrate standard PV modules in a wooden prefabricated façade component.

The two examples are meant to stress the importance of designing new BIPV elements as part of the building itself since the very first step of the design and optimization processes. More specifically in the second example, the authors would like to emphasize the possibility of integrating PV elements in pre-fabricated building components already available on the market such as wood-structured insulated façades, which are quite common in the north of Italy and in many European regions.

The following paragraphs describe, step by step, the processes followed for the development of the two prototypes.

\subsection{THE PROTOTYPE OF A NEW ANGLE SELECTIVE TRANSPARENT BIPV FAÇADE COMPONENT}

This chapter presents a new prototype of BIPV semi-transparent façade developed at Fraunhofer ISE in the framework of the European project Cost Effective (Convert façade into multifunctional, energy gaining components, http://www.cost-effectiverenewables.eu/). 


\subsubsection{BACKGROUND AND MOTIVATION}

In façade construction, in particular for high-rise buildings, the portion of the glazed area of the façade increases continuously. Indeed, architects are fond of transparency, the sun and the contact with the city and the context. This causes the positive effect of higher daylighting of the internal space and the reduction of energy consumption for artificial lighting but, on the other hand, produces the risk of overheating and/or high cooling loads. For that reason, solar protection is necessary.

It is very common in Central or North Europe to control the solar gains with external shading systems (for example venetian blinds). This solution has some advantages for residential houses (family houses), because of the high efficiency and the low cost of installation, but is not suitable for high-rise buildings and windy locations. Also, traditional exterior shadings do not produce energy.
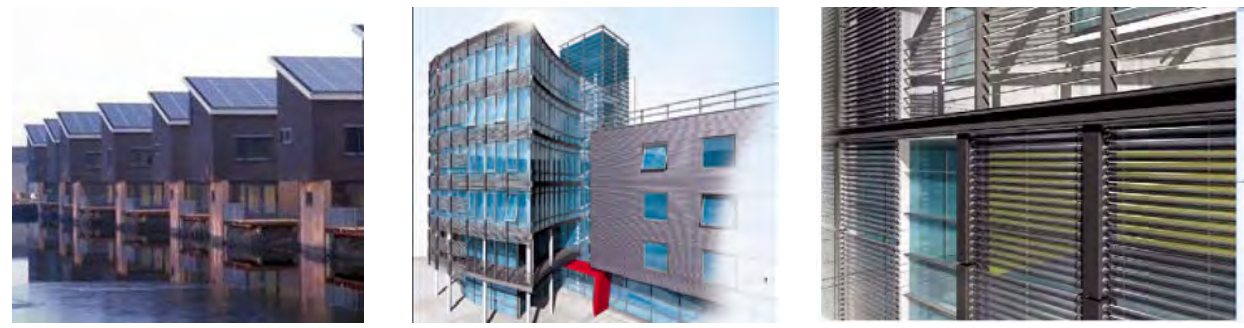

Fig 4.1: Systems Integration in building. Source: 1) BEAR Architects, 2) Viessmann, City of Tomorrow in Sweden, 3) Viessmann, University of Stuttgart.

The new angle selective see-through PV-façade proposed (Fig 4.1) combines four important tasks in one element:

- solar protection,

- glare protection,

- visual contact,

- PV-system integration for electricity.

These four tasks are completely integrated in the function of the façade and thus do not reduce the architectural goal of the glazed façade. Furthermore, the view from the interior to the exterior is guaranteed.

\subsubsection{METHODOLOGY (EXTRACTED FROM [4.5])}

The first step was to define and evaluate the main variables of the system. A certain number of parameters were identified such as the characteristics of the glass, the thickness of the different layers and the sun angles. To achieve a good visual transmission a mathematical and physical analysis of the systems was done to optimize the geometry. The optimization was then performed by defining different equations and implementing them into an "Excel" table and into a "Mathematica" notebook. Depending on the different main variables different geometries were obtained. 
The second step was to simulate the different geometries and to reproduce them in the RADIANCE simulation packages [4.4] in order to assess the visual comfort (visual contact to the exterior and glare protection) as well as the quality of daylighting. Different materials and different geometries were evaluated for the visual comfort optimization.

To validate the RADIANCE simulation model and to understand the real effects of the geometry and the material, a sample was produced with the contribution of a German glass manufacturer. The $1 \times 1$ meter prototype was tested and measured in the laboratory of the Fraunhofer Institute ISE to determine the optical properties of the complete system (transmission, reflectance etc).
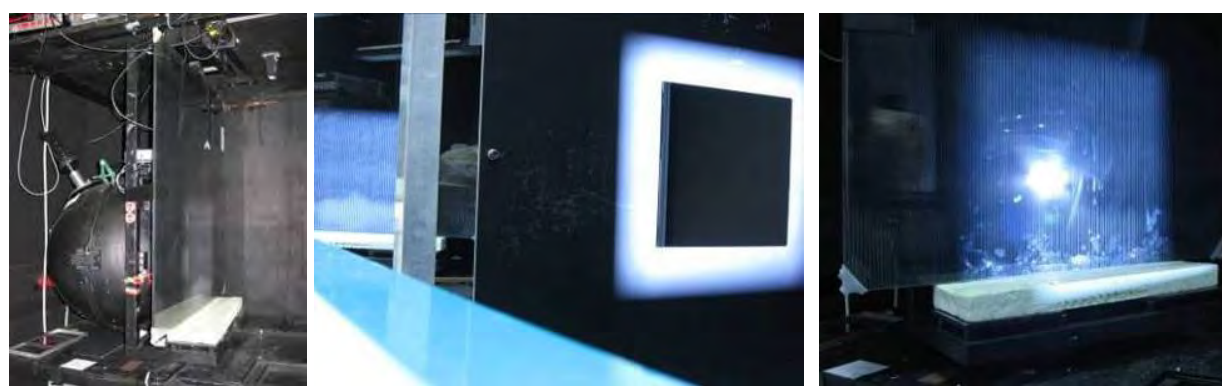

Fig 4.2: The pictures show the indoor measurement carried out in the TOPLAB laboratory at Fraunhofer ISE. An Ulbricht Sphere was used to assess the transmission of the façade.

The measured data confirm the results obtained previously by the mathematical analysis and were finally used to validate the radiance model.

The fourth step was to assess the impact of the new angle selective façade in a real building space concerning daylight level and light energy saving. The software Daysim (developed by Christoph Reinhart [4.1]) combined with RADIANCE was used for this purpose.

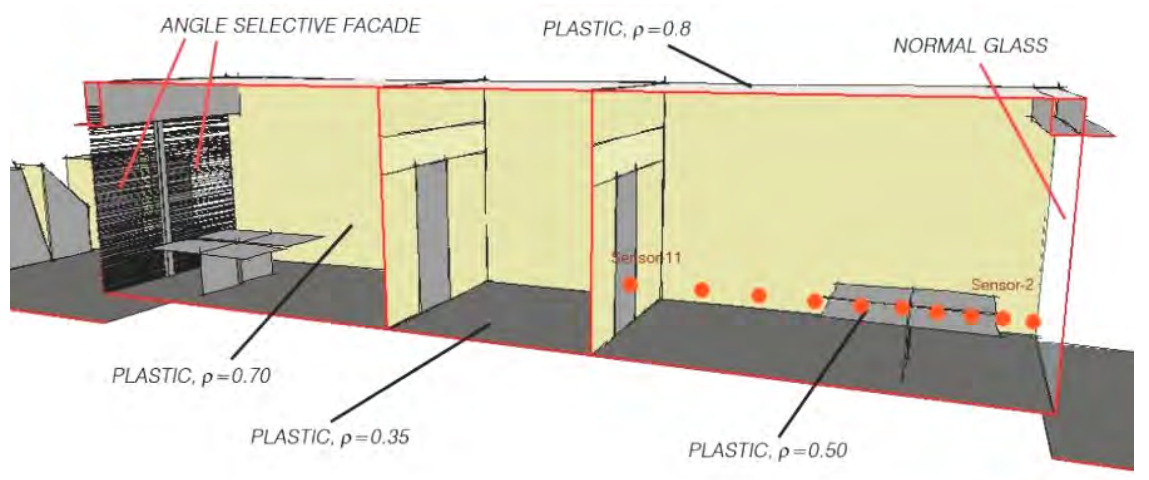

Fig 4.311: Section of the simulated office. The angle selective façade was faced to the south and a reference room was chosen to the north. Eleven sensors for each part were placed in the middle of the room.

The fifth step, was done to evaluate the total g-value (total solar heat gain) of the new glazed façade and to simulate the effect in thermal comfort (internal temperature) for 
the analysis of an office space. The new version of the software ESP-r [4.3] [4.8] was used for this analysis. After these five main steps it was possible to freeze the passive (without photovoltaics) design of the façade.

With the integration of photovoltaic technologies, the system becomes more complex due to the introduction of new parameters (such as electricity production, durability, dependency on the solar irradiation). Different available thins film technologies were evaluated and a second optimization was done in order to assess the light absorption of the active layers (with photovoltaics).

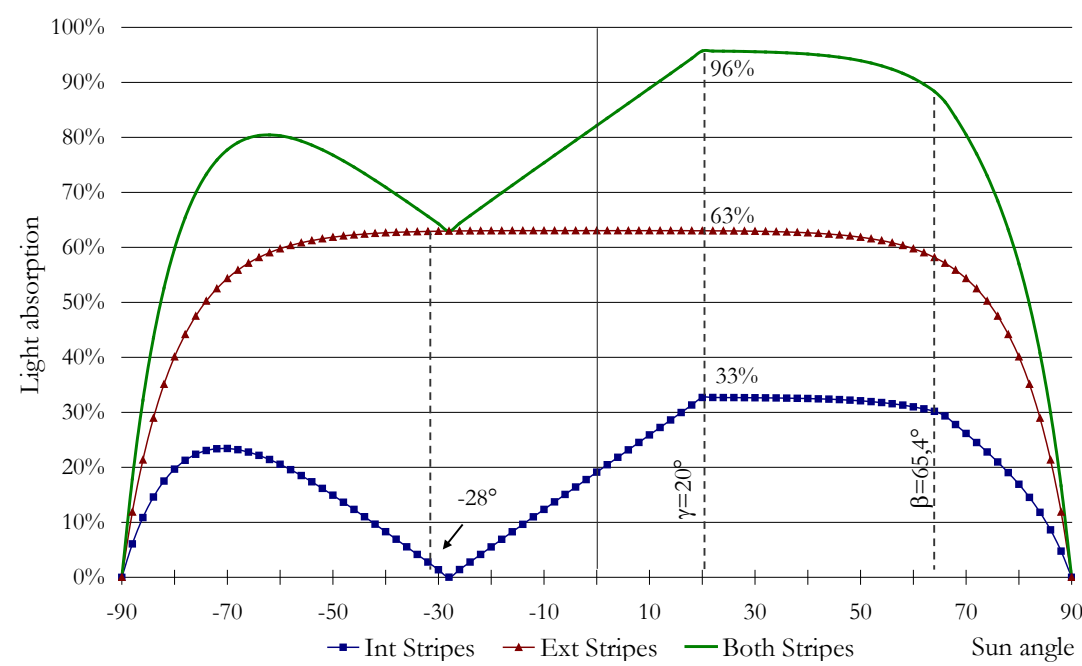

Fig 4.3: Light absorption of the two different layer stripes and of the complete system.

After a new iterative process, a second generation façade design was frozen. New laboratory measurements were carried out in order to characterize the energy production of the system.

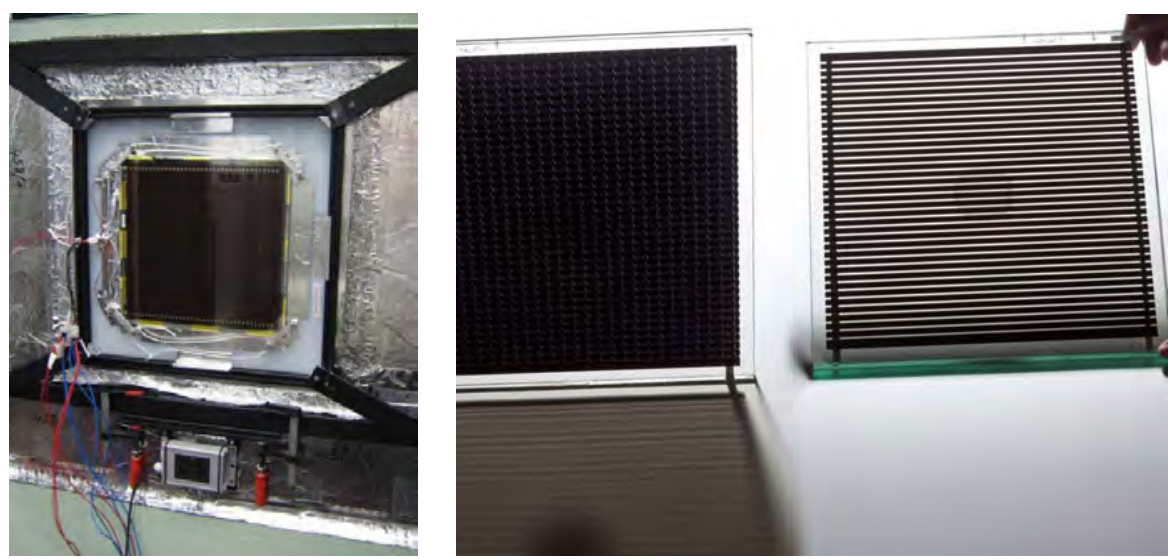

Fig 4.412: Fully functional BIPV prototype mounted in the test rig at Fraunhofer ISE premises [4.9].

The final step will be to expose the new active prototype to the outdoor environment in order to monitor the real characteristics of the façade. 
The following diagram summarizes the main steps carried out during the optimization and the manufacturing process of the BIPV prototype. It is possible to see two different paths: on the left, the R\&D process is focused on the optimization of the passive component (passive shading device for transparent façades); on the right, the development refers to the active system when photovoltaics are integrated into the component.

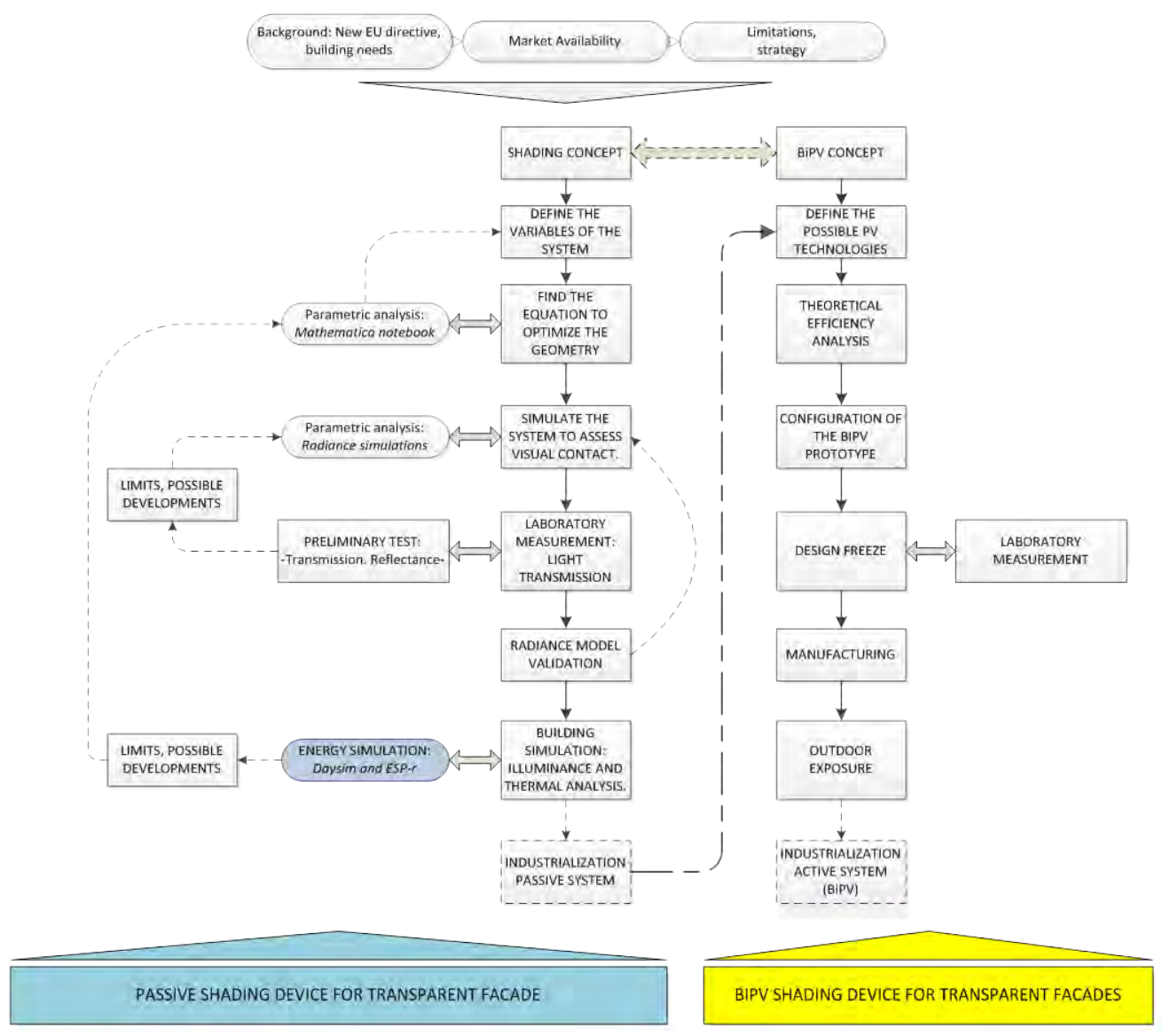

Fig 4.5.: The main steps carried out during the optimization and the manufacturing process of the BIPV prototype.

\subsubsection{DESCRIPTION OF THE BIPV SYSTEM}

The new façade system is a static sun protection glazing façade, which can be produced using the usual production technologies for windows and glazing units.

It consists of at least two laminated glass panes with two series of opaque stripes, one between the two laminated glasses and the second at the inner surface of the façade. It is easily installable in conventional double or triple glazing units in order to achieve the requested performance. Due to the different refractive indices of air and glass together with the specific position of the opaque stripes on the glass, the new façade offers high solar control and can protect the occupants against glare. The visual contact with the outside is also guaranteed and varies with the viewing direction. 


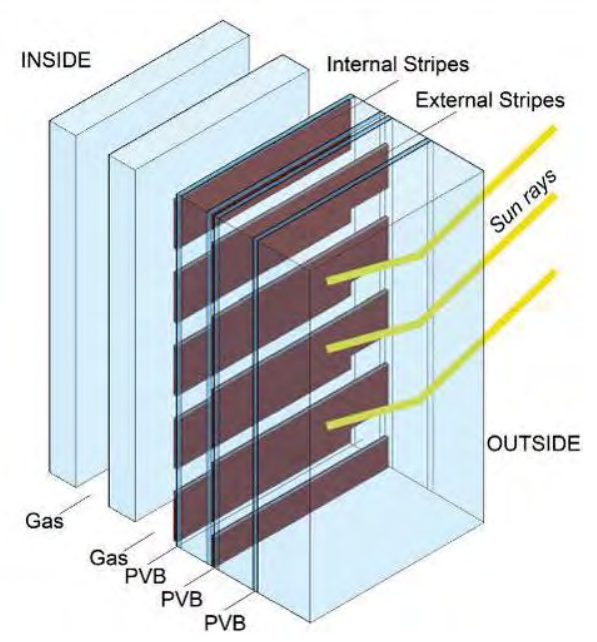

Fig 4.613: Scheme of the new system

The opaque stripes can be produced in different materials and colours, depending on the architectural concept and on the shading requirements: dark colours are favoured to maximize the shading and anti-glare performance.

The visual transmission of the system strictly depends on the view direction (see [4.5]): when looking downward (left picture) or perpendicular to the façade (picture in the middle), the transmission is very high, but when looking upward directly to the sun (right picture) the transmission is zero.
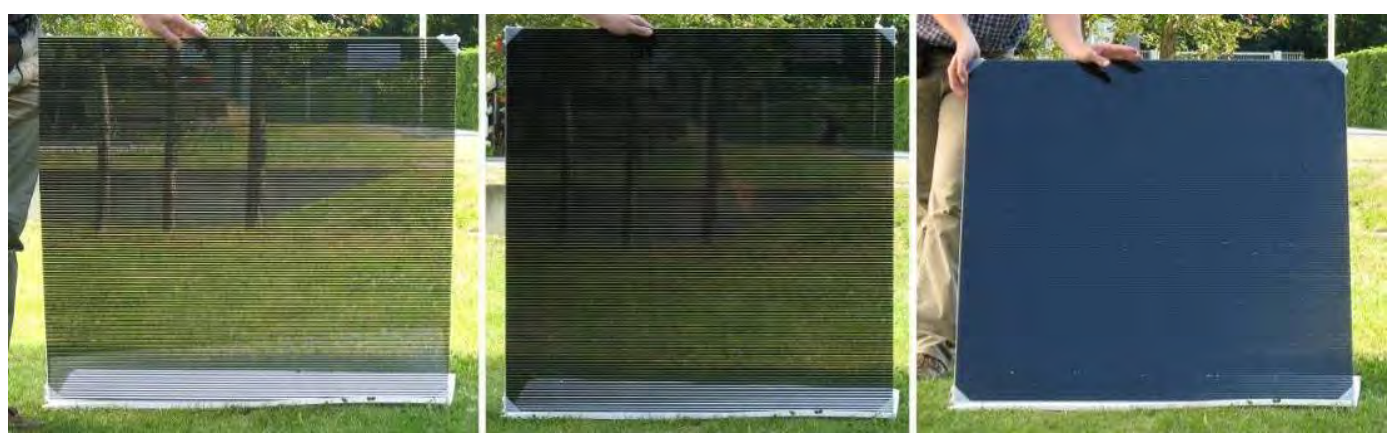

Fig 4.7: First prototype of the new angle selective façade (without PV functionality).

\subsubsection{FAÇADE INTEGRATION}

The new angle-selective façade can be used either as a stand-alone system for a glazed façade or as an extra shading device layer. It can also be used for retrofitting.

The new PV façade can be installed as a sliding external shading device to protect, depending on the internal comfort, the office space and the windows or as a movable panel. 

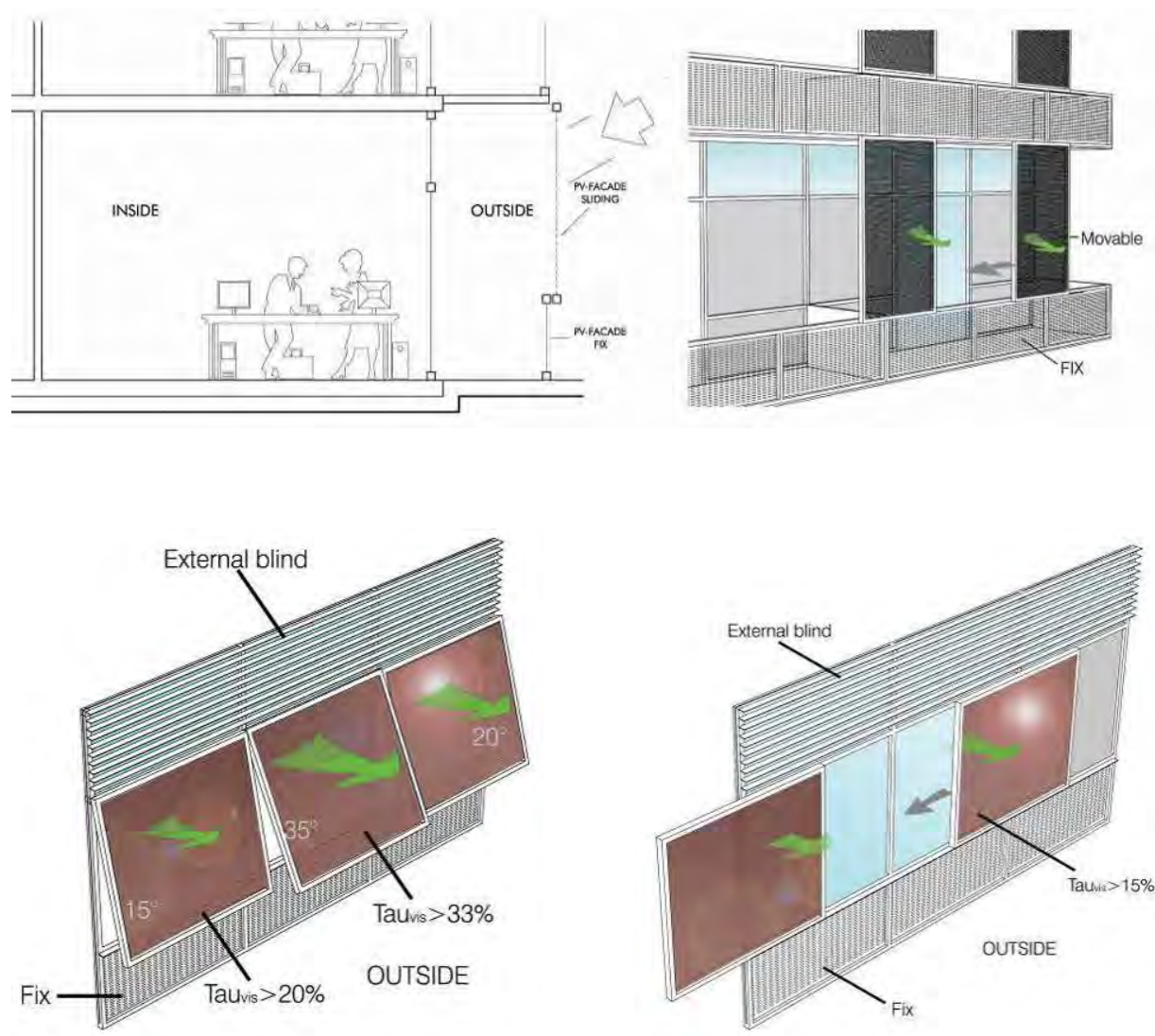

Fig 4.814: The pictures present an idea of the integration of the new façade as an external shading device. 


\subsection{THE PROTOTYPE OF A WOODEN BIPV FAÇADE COMPONENT}

The prototype of a wooden BIPV façade component was developed within a research project co-financed by the Province of Trento (Italy) and thanks to the collaboration between the research Institute for Renewable Energy of Eurac and a network of local enterprises called Chi Quadrato.

The diagram below synthetically shows the process that guided the development of the prototype, from the concept to the construction.

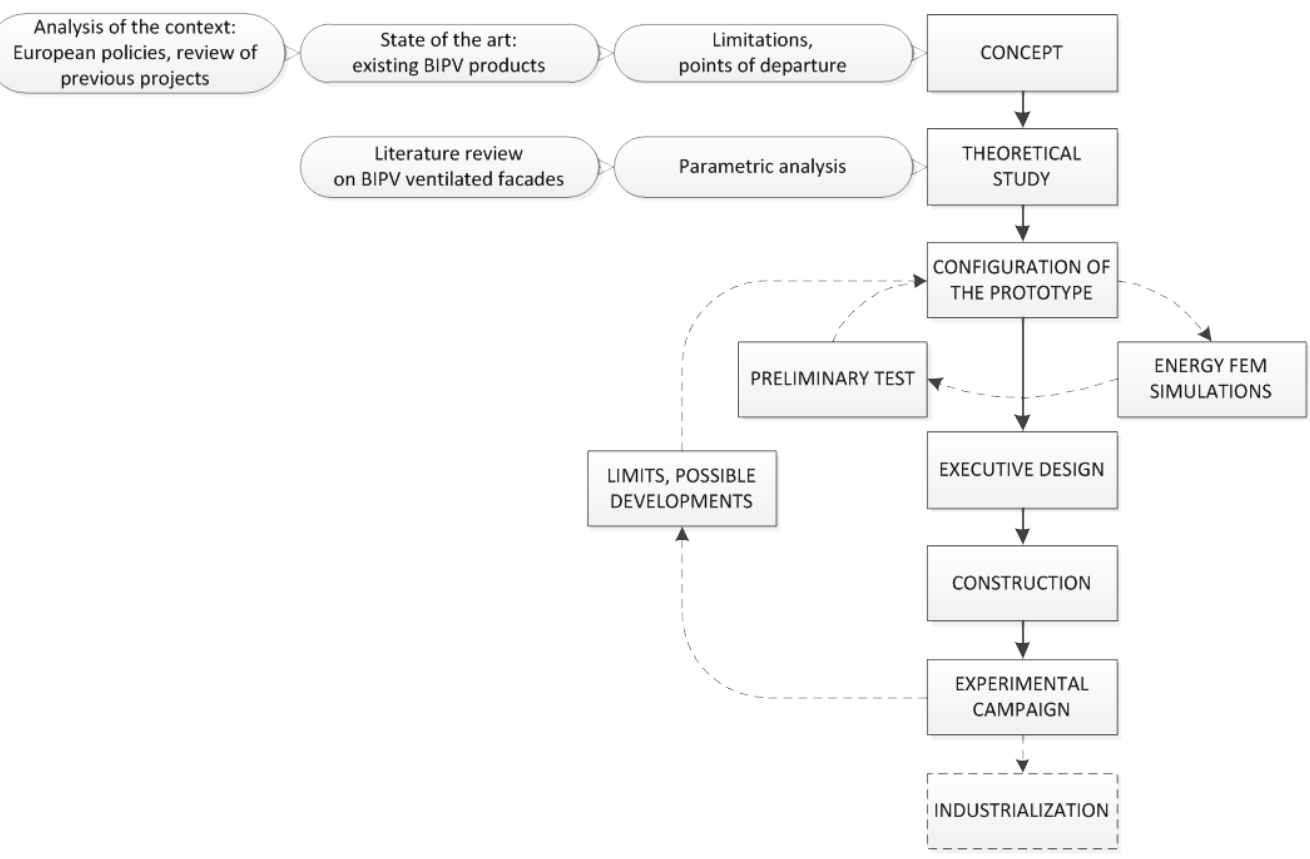

Fig 4.9: The process that guided the development of the prototype, from the concept to the construction.

\subsubsection{CONCEPT}

The building envelope was not only conceived as a passive solution but also as an active system able to contribute to satisfy the demand of electricity since a PV system is integrated in it. It is important to note that the costs still represent a barrier for the use of PV as a common building material [4.13]. The prefabrication of an envelope component that integrates a PV system could reduce these costs and, at the same time, enhance the overall quality as well as the energy performance.

Having all this in mind, a concept of an innovative prefabricated wooden façade component with integrated PV was conceived and developed.

The prototype was designed as a multifunctional prefabricated product, as encouraged by the Task 7 of the IEA PV Power System Programme [4.11], which identified in 
standardization, prefabrication, and "low cost" the greatest opportunities for new product developments.

Four key concepts led to the development of this prototype:

- Multi-functionality, as it fulfils several building requirements and produces electricity

- Sustainability, since it couples the PV technology and wood, which is an autochthonous material considering the Alpine region where it has been developed

- Integration, because the PV system is not added as an additional layer to the building envelope, but as a part of it

- Prefabrication, which allows a reduction of costs, a greater speed of construction, and an enhancement of quality.

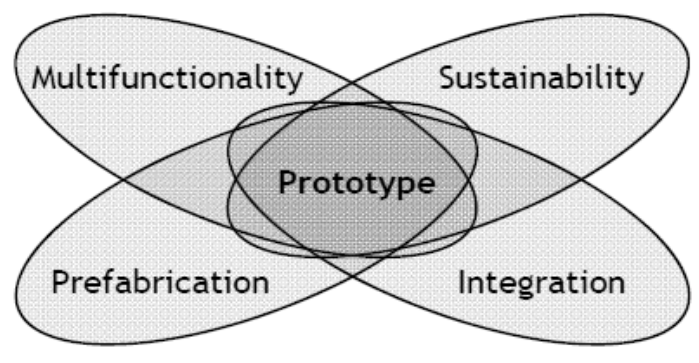

Fig 4.10: The diagram shows the four key characteristics of the prototype.

\subsubsection{DESCRIPTION OF THE PROTOTYPE}

The BIPV prototype is made of three main layers: a structural part of framed wood panel with thermal insulation (number 1 to 8 in Fig 4.11), an air gap for the natural ventilation (number 9 in Fig 11) and an external finishing which is the PV system (number 12 in Fig 11).

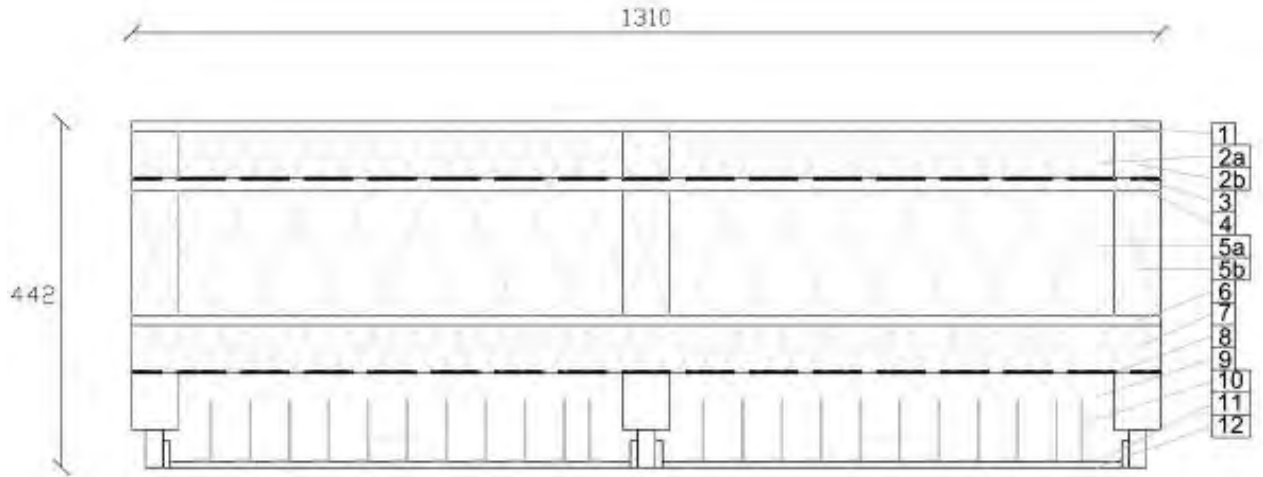

Fig 4.11: Horizontal section of the BIPV prototype 
A heat sink system is applied to the backside of the PV modules in order to increase the heat transfer between the PV modules and the air gap, lowering the PV temperature. In fact, a temperature increase in the PV module causes efficiency drops: lowering the PV operating temperature means enhancing the PV energy performance.

\subsubsection{METHODOLOGY}

The configuration of the prototype is the result of a theoretical study focused on the energy performance of the component. And since it is a BIPV prototype, its energy performance regards both the electrical production of the PV system and the thermal characteristics of the building envelope [4.12]. Therefore, the methodology used to define its configuration is a parametric analysis which includes both PV and building related aspects. It considers five parameters as independent variables, which are: the PV technology, the air gap ventilation, the thickness of the air gap, the heat exchange features, and the materials that were applied. The analysis considers the PV efficiency and the thermal transmittance as dependent variables: the first one is related to the module's temperature, which is evaluated through energy simulations, while the second one is assessed both in accordance with the UNI EN ISO 6946 and through an experimental campaign. A FEM energy simulation campaign was carried out to assist the design phase in order to optimize the overall energy behaviour of the prototype. The formal architectural integration issue is also an essential factor which was taken into account during the design phase. Particular care was put in the choice of the PV modules, which replaced the traditional external cladding. A "standard" module was chosen rather than a costume-made product in order to be coherent with the concept of standardization to reduce costs. An analysis of the standard products available on the market was carried out and, taking into account several architectural criteria, and a thin film module based on CIGS technology was selected. The aim was to find a homogenous surface, as coherent as possible with the rest of the standard wooden prefabricated buildings.

\subsubsection{EXPERIMENTAL CAMPAIGN}

A specimen of the designed prototype was tested at the Eurac laboratory in a guarded hot box that is equipped with a sun simulator (see Fig 4.12) [410]. The experimental study was divided in two phases: the first one for the measurements of steady-state thermal transmission properties (in night conditions) and the second one for the measurement of the PV performance on the basis of the PV temperature (in daytime conditions), considering different configurations. The experimental part allowed a validation of the theoretical models and of the energy simulations carried out in the previous phases. 

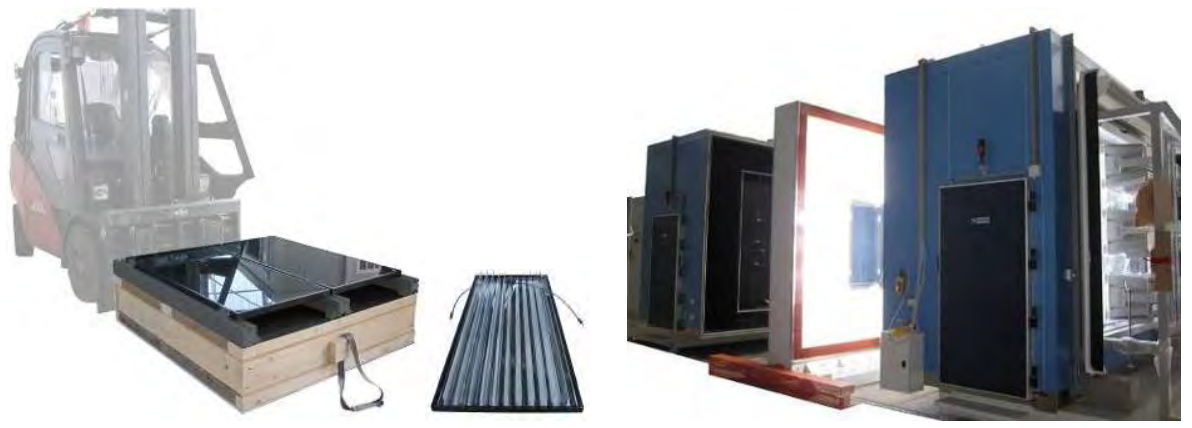

Fig 4.12: The picture on the left shows the tested specimen and the PV module with fins attached on the backside. As for the image on the right, it displays the Eurac guarded hot box with the integrated sun simulator.

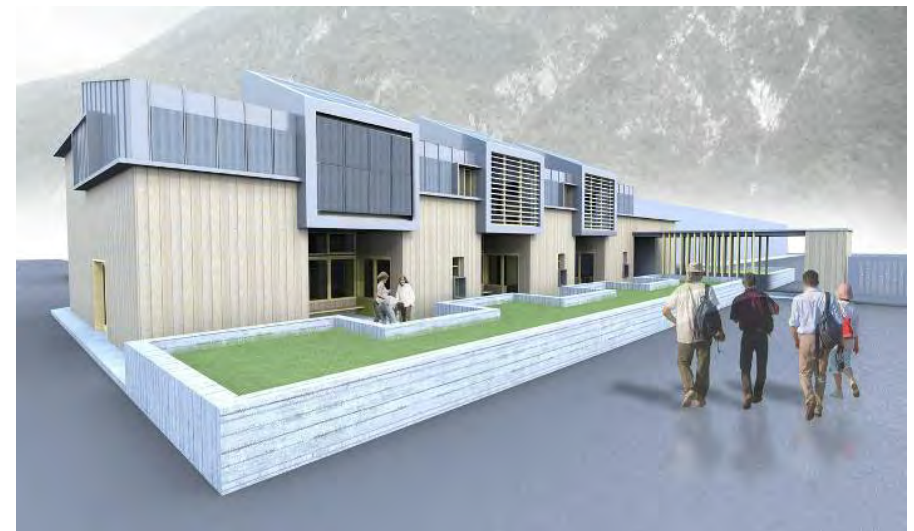

Fig 4.1315: Rendering of an elementary school made of wooden prefabricated elements, including the BIPV prototype on the left. [re-arrangement L. Maturi from rendering Studio Arch. Frate]

The experimental results highlighted the advantages and limits of such a prototype, allowing to better plan the actions needed for future developments before facing the industrialization phase. 
5. EXAMPLES OF EXISTING PRODUCTS FOR BUILDING INTEGRATION 

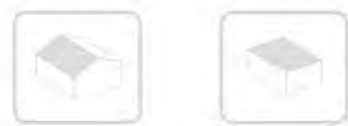

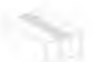

\section{Lumeta Lumeta Power Ply}

Irvine HQ, 17182 Armstrong Ave.,

Irvine, CA 92614

www.lumetasolar.com

Lumeta PowerPly is a Building Integrated Photovoltaic module for low slope applications. Lumeta ${ }^{\mathrm{Tw}}$ utilizes monocrystalline cells to maximize energy output per roof area, and a standard EVA based cell encapsulation process. The fiberglass-reinforced plastic (FRP) substrate in the PowerPly ${ }^{\mathrm{Tm}}$ design provides needed rigidity to the module, replacing the TPT ${ }^{\mathrm{TM}}$ (Tedlar ${ }^{\varpi}$ / Polyester $/$ Tedlar $^{\circ}$ ) flexible substrate used in traditional modules. This high efficiency technology is enhanced by Lumeta's adhesive backing material, which eliminates the need for rack mounting systems, yielding seamless integration with the roof. The adherence properties of this adhesive material exceed all wind uplift requirements for roof mounted modules, and its chemical composition is compatible with most roofing surfaces. This direct roof application reduces installation time by about $60 \%$ and Balance of System (BOS) costs by up to $50 \%$.

\begin{tabular}{|l|c|}
\multicolumn{2}{|c|}{ PV "Integrability" characteristics } \\
\hline Multifunctional element & + \\
\hline Shape \& size flexibility & - \\
\hline Pattern choice & - \\
\hline Colour choice & - \\
\hline Jointing/ frame & + \\
\hline Availability of dummies & - \\
\hline Complete construction system & - \\
\hline
\end{tabular}

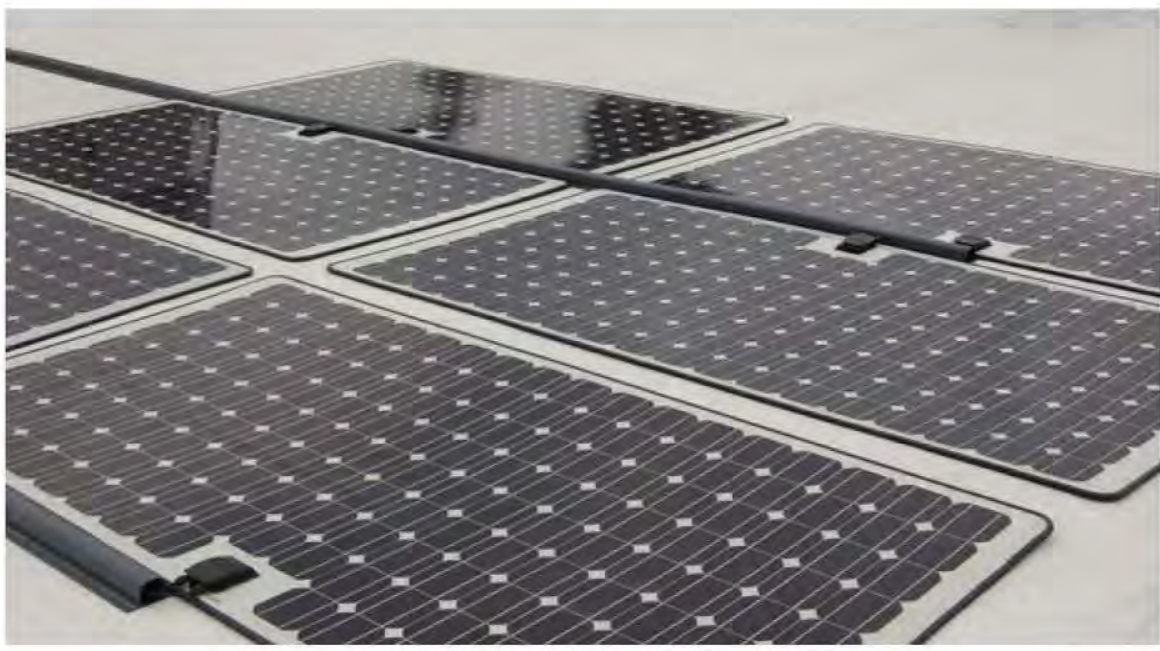

Lumeta PowerPly integrated on flat roof, (C Lumeta

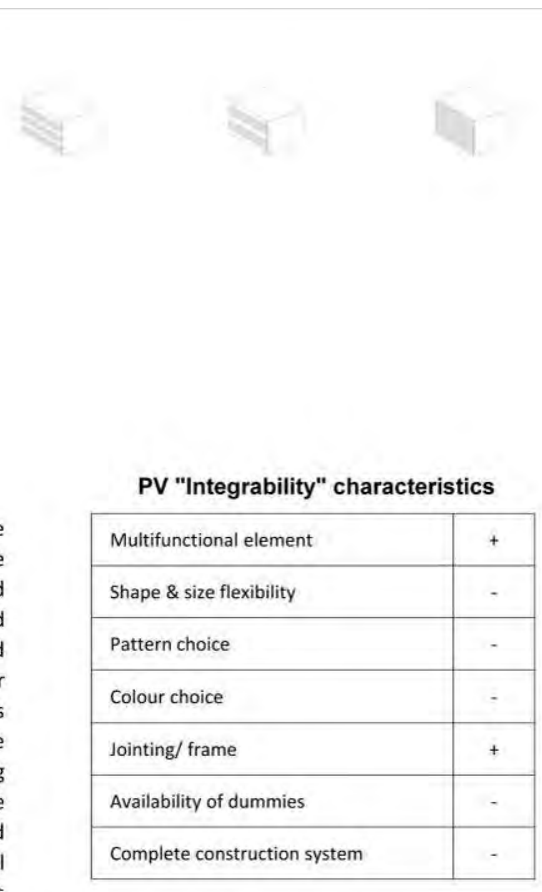




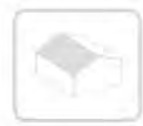

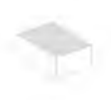

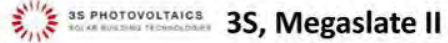

Schachenweg 24, CH-3250 Lyss, Switzerland

info@3-s.ch

www.3s-pv.ch

PV "Integrability" characteristics

The MegaSlate II" Solar roof system replaces conventional roof tiles either as a complete or partially integrated roofing material.

It involves frameless PV laminates which are used as large solar tiles. Each module is laid on two hooks, which are fixed to a special lathing. Sealing is achieved thanks to a vertical overlapping and vertical profiles that collect rain water. Custommanufacturing modules allow integration with roofing elements such as skylights or chimneys. The manufecturer suggests to use the MegaSlate II system for roof surfaces with an angle of inclination of at least $20 \%$

The modules can be installed on wood structured roofs very easily and quickly. Dimensions are limited to $1300 \times 875 \mathrm{~mm}$ but in addition to the PV modules, solar thermal collectors and skylight can be inserted in the construction always maintaining the aesthetics and homogeneity of the product. Dummy modules are also available.
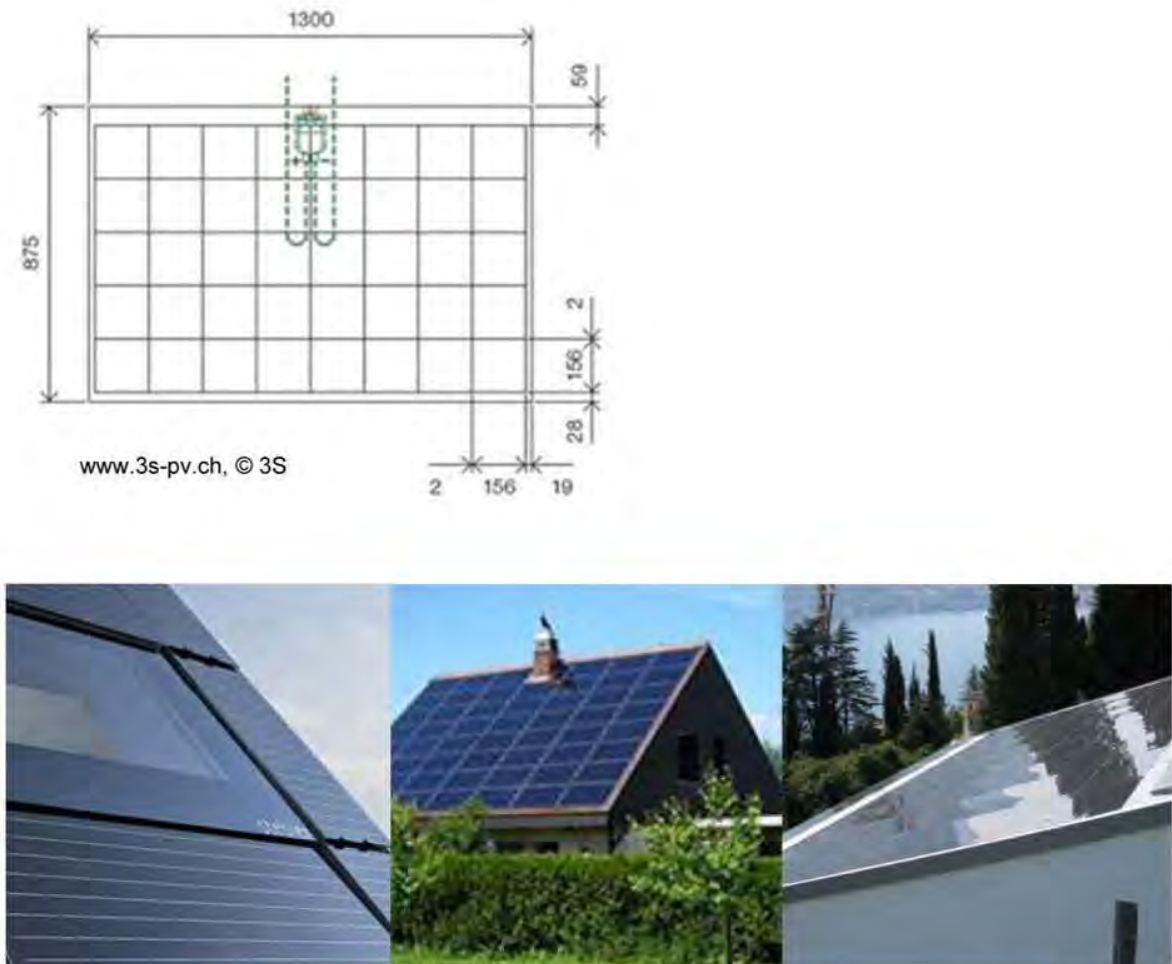

Frameless MegaSlate II,

House in Cudrefin (FR-CH)

(C) 35

\begin{tabular}{|l|c|}
\hline Multifunctional element & + \\
\hline Shape \& size flexibility & $+1-$ \\
\hline Pattern choice & + \\
\hline Colour choice & - \\
\hline Jointing/ frame & + \\
\hline Availability of dummies & + \\
\hline Complete construction system & + \\
\hline
\end{tabular}




\section{SOLRFPPMU: Solaire France, Sunstyle}

Site Tecnosud, 280 Rue James Watt, 66000 Perpignan, France info@solairefrance.fr

www.solairefrance.fr

The Sunstyle system is a multipurpose solar system which allows to generate solar current while meeting standards of functionality, performance and high durability. In fact this product is an evolution of a standard building PV element for roofs.

The tiles are structural components whose manufacturing process was especially developed and certified. The crystalline solar cells are coated with a layer of EVA (Ethyl Vinyl Acetate) and then laid between a soaked frontal glass and a tedlar sheet at the back. The edges are closed, without framework, to avoid the penetration of moisture in order to ensure the durability of the elements. The modularity of the systems is thought for roo and it is easy to install together with non active systems (dummies). The Sunstyle system can be also used for retrofitting

by substitution of existing roof tiles.

PV "Integrability" characteristics

\begin{tabular}{|l|c|}
\hline Multifunctional element & + \\
\hline Shape \& size flexibility & + \\
\hline Pattern choice & - \\
\hline Colour choice & - \\
\hline Jointing/ frame & + \\
\hline Availability of dummies & + \\
\hline Complete construction system & + \\
\hline
\end{tabular}

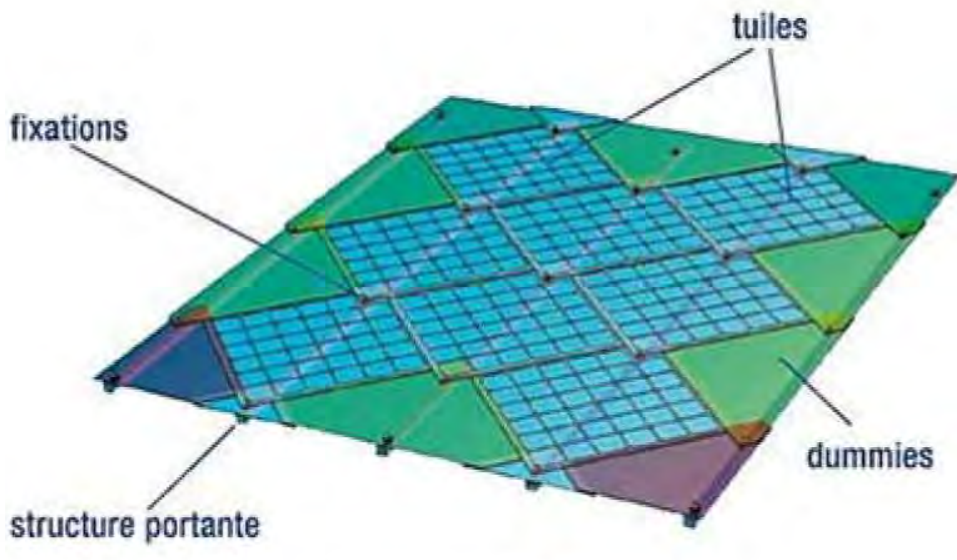

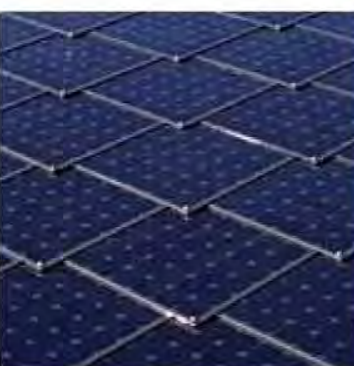

Sunstyle modules,

(c) Solaire France

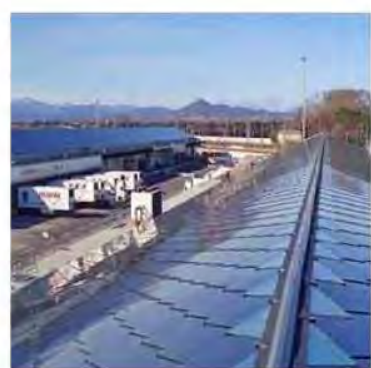

Saint-Charles International, (c) Solaire France

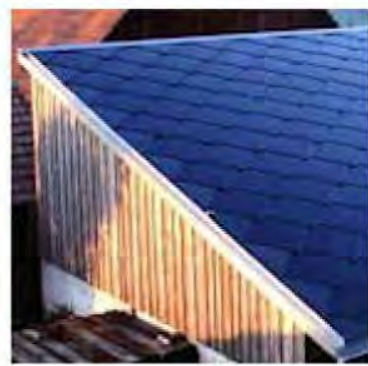

www.solairefrance.fr C) Solaire France 


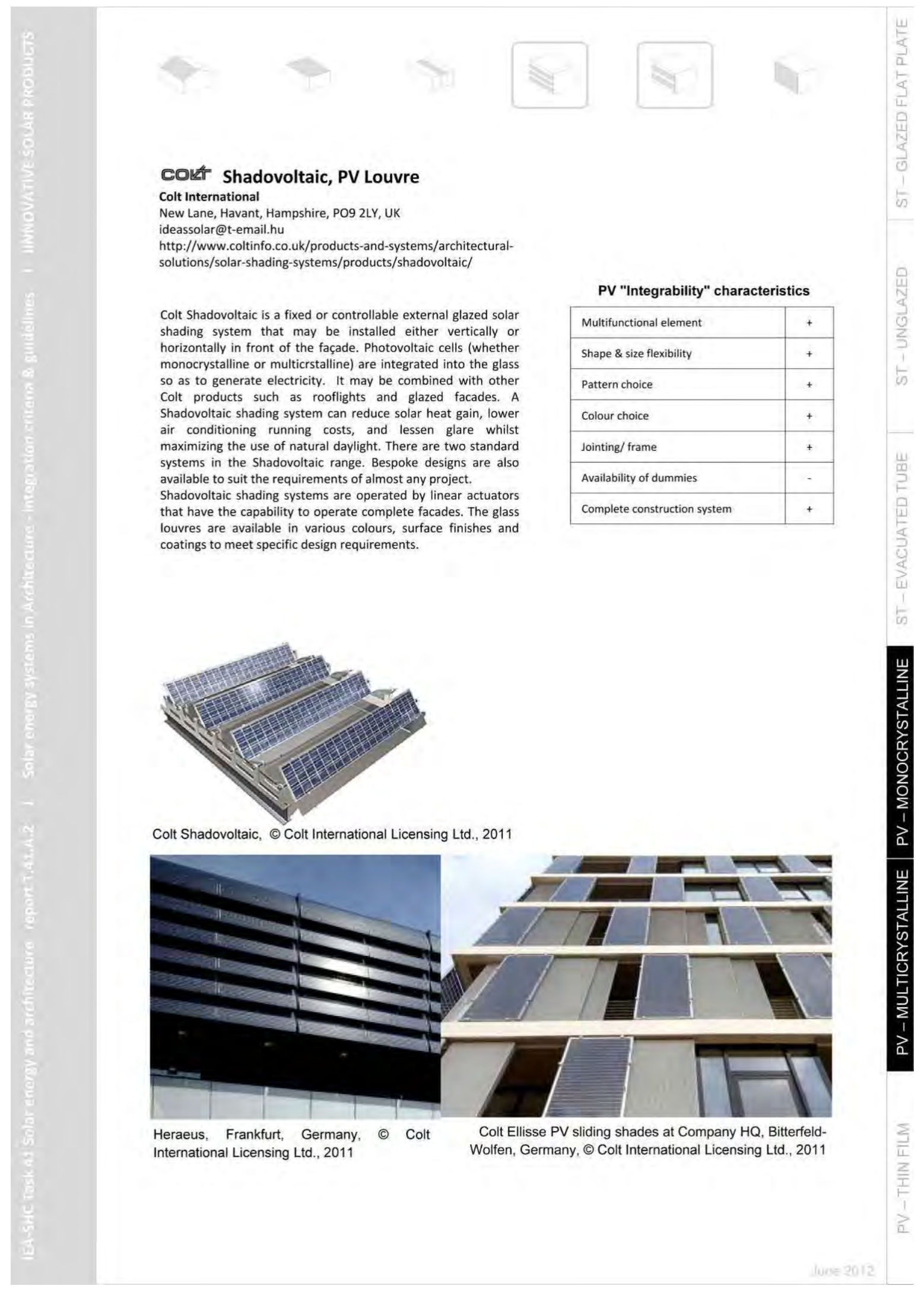




\section{TMT Solar Tile Systems}

IdeaS Solar Ltd. Hungary

Petőfi S. út 49., Harsány $\mathrm{H}-3555$ Hungary

ideassolar@t-email.hu

http://www.ideassolar.hu

PV "Integrability" characteristics

Solar cell roof tiles produce electricity by altering solar energy, and as regards their application, their primary benefit is that they can be applied as either solar cell roof tiles that have a form, size, color, and identical fixing points identical with the type and form of any existing roof tile or roof covering, or they can be the actual roof tiles piece by piece on a particular roof. The solar cell roof tiles are equipped with their own special chargeable batteries, thus there is no need for external batteries and/or a separate room for the storage of batteries. The TMT Solar Tile Systems ${ }^{\star}$ units are also manufactured without batteries, and in such case they supply electric appliances directly connected to them. No separate electricity collecting rail or cable connections are required for the TMT Solar Tile Systems ${ }^{\oplus}$ units, because they are integrated in the appliance. Its weight is only third of any roof covering, so that the roof is statically not burdened, because the weight of the raw materials, the concrete, and the roof tiles is compensated.
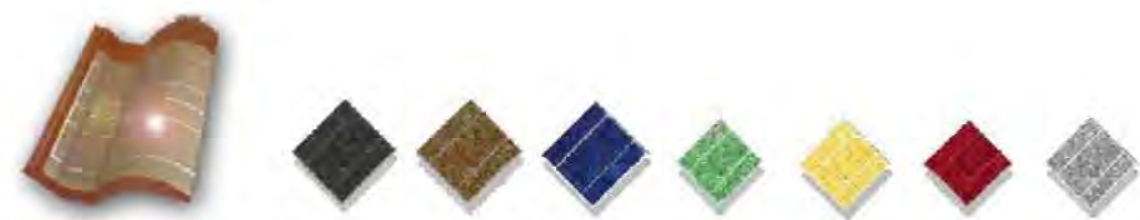

Variations of color, (C) IdeaS Solar
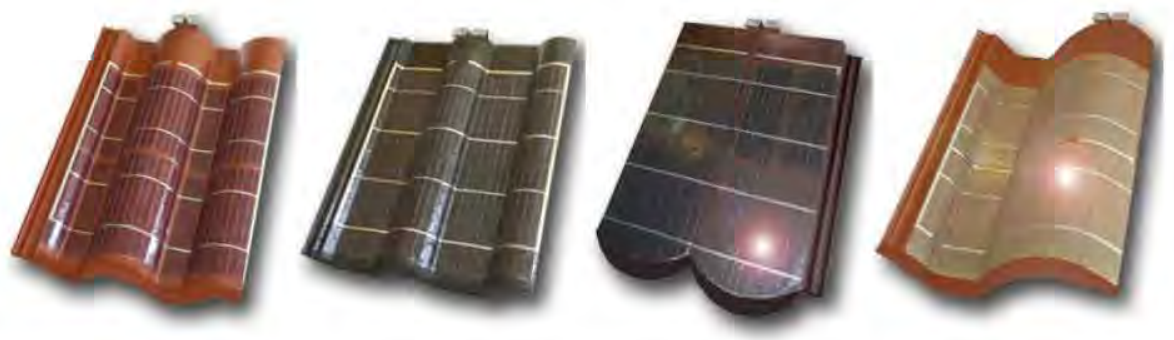

Variations of shape of the tile, @ IdeaS Solar

\begin{tabular}{|l|c|}
\hline Multifunctional element & + \\
\hline Shape \& size flexibility & + \\
\hline Pattern choice & + \\
\hline Colour choice & + \\
\hline Jointing/ frame & + \\
\hline Availability of dummies & + \\
\hline Complete construction system & + \\
\hline
\end{tabular}




\section{COLي Solar Window Shutters}

\section{Colt International}

New Lane, Havant, Hampshire, PO9 2LY, UK

ideassolar@t-email.hu

http://www.coltinfo.co.uk/products-and-systems/architectural-

solutions/solar-shading-systems/products/shadovoltaic/

Colt has developed a Solar Window-Shutter that can be installed on either old buildings during refurbishment, or during the construction process on new buildings. It

provides highly efficient external sun shading generates electricity from a renewable source by optimising the use of daylight, provides thermal protection and burglar protection, as well as weather protection for windows. In new buildings the Window-Shutter effectively replaces the roller shutter, which does not provide sufficient thermal protection and can also disturb external safety guards. The solar integration with wooden frames also bypasses the need to use energy intensive aluminium.

Two parallel lever arms move the Solar Window-Shutter in

a half circular movement to the side, so that the solar active side is always pointing towards the sun in either the open or closed position. With wide window formats, the Solar Window-Shutters can be installed as a sliding mechanism. The mechanism is entirely covered by the frame, making the Window-Shutter acceptable for use on historical monuments.

PV "Integrability" characteristics

\begin{tabular}{|l|c|}
\hline Multifunctional element & + \\
\hline Shape \& size flexibility & + \\
\hline Pattern choice & + - \\
\hline Colour choice & $+/-$ \\
\hline Jointing/ frame & + \\
\hline Availability of dummies & $+/-$ \\
\hline Complete construction system & + \\
\hline
\end{tabular}

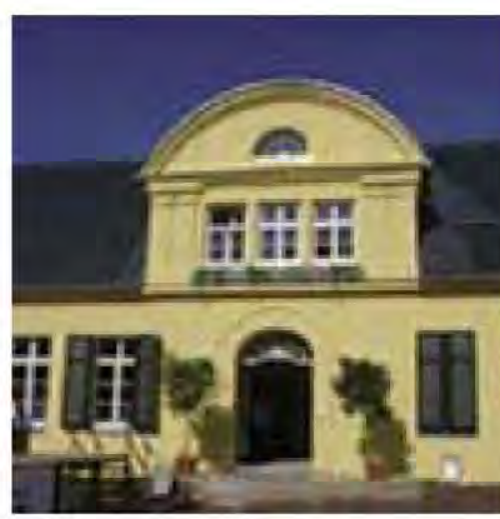

(c) Colt
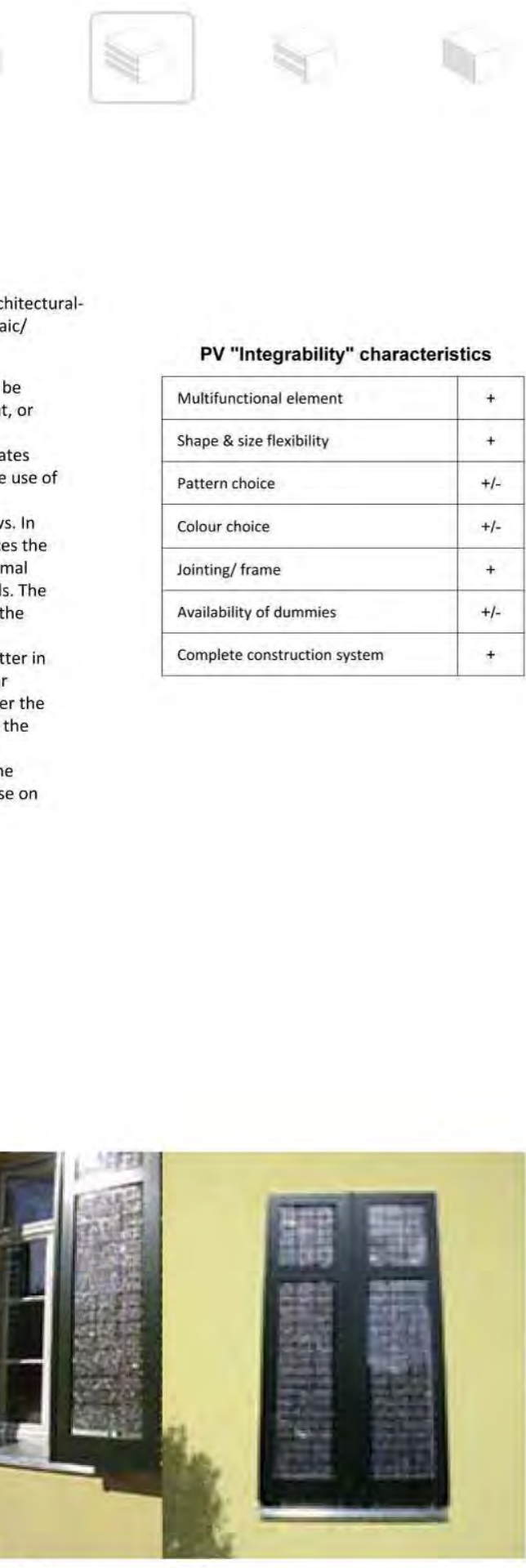


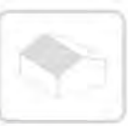

\section{SRS SRS Energy Sole Power Tile}

afeinstein@srsenergy.com www.srsenergy.com

The SRS Energy Sole Power Tile ${ }^{\mathrm{TM}}$ is the first curved solar power product to obtain UL certification and a listing on the California Energy Commission's list of approved solar modules. The Sole Solar Power Tile is specifically designed to replace tradition clay tiles. Due to the thin film laminate the colour is currently limited to dark blue.

PV "Integrability" characteristics

\begin{tabular}{|l|c|}
\hline Multifunctional element & + \\
\hline Shape \& size flexibility & - \\
\hline Pattern choice & - \\
\hline Colour choice & - \\
\hline Jointing/ frame & + \\
\hline Availability of dummies & + \\
\hline Complete construction system & + \\
\hline
\end{tabular}

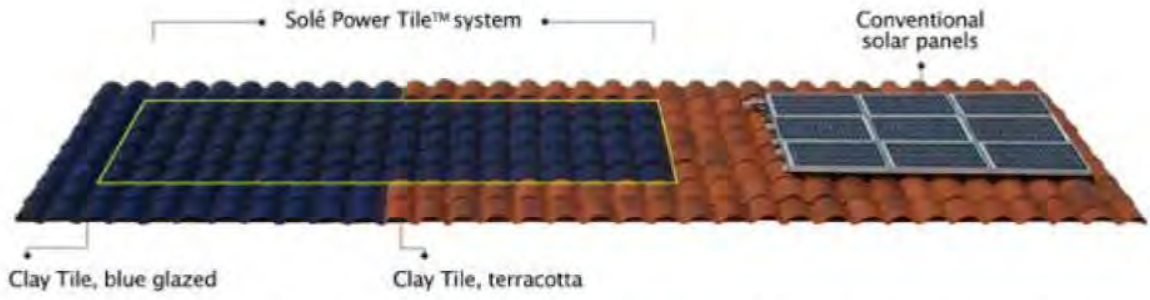

Sole Power Tile system with blue glazed clay tiles, terracotta clay tiles and in comparison with conventional solar panels added on the tiles, (C) SRS Energy
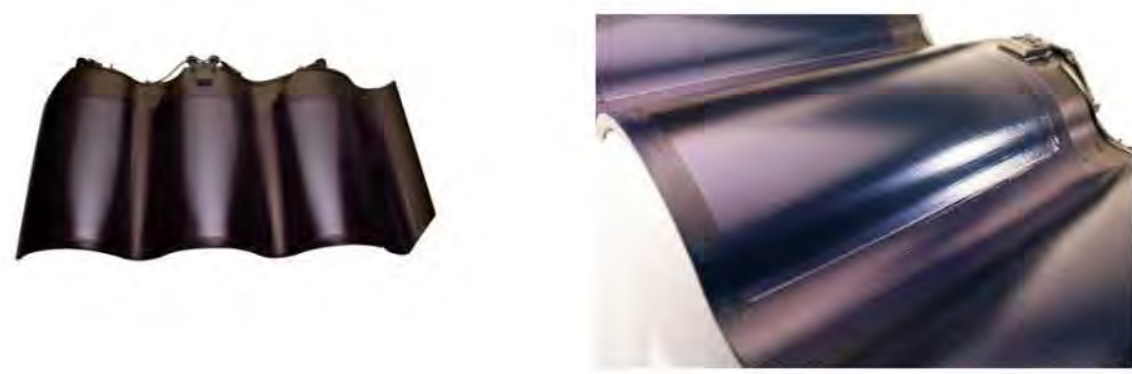

Close-up photos of Sole Power Tile, (c) SRS Energy 


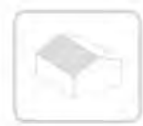

\section{UIII-SOLAR. Unisolar - Power shingle}

United Solar Ovonic LLC

3800 Lapeer Road, Auburn Hills, MI 48326, USA

info@uni-solar.com

www.uni-solar.com

PV "Integrability" characteristics

Unisolar's Power Shingle. The shape, size and pattern of the solar laminate imitate traditional asphalt roof shingles. Unisolar is lightweight and flexible laminates integrated into laminates that are designed to look like asphalt shingles. The PowerShingle product features laminates that are glass-free and encapsulated in UV-stabilized, weather-resistant polymers.

\begin{tabular}{|l|c|}
\hline Multifunctional element & + \\
\hline Shape \& size flexibility & + \\
\hline Pattern choice & - \\
\hline Colour choice & - \\
\hline Jointing/ frame & + \\
\hline Availability of dummies & + \\
\hline Complete construction system & + \\
\hline
\end{tabular}

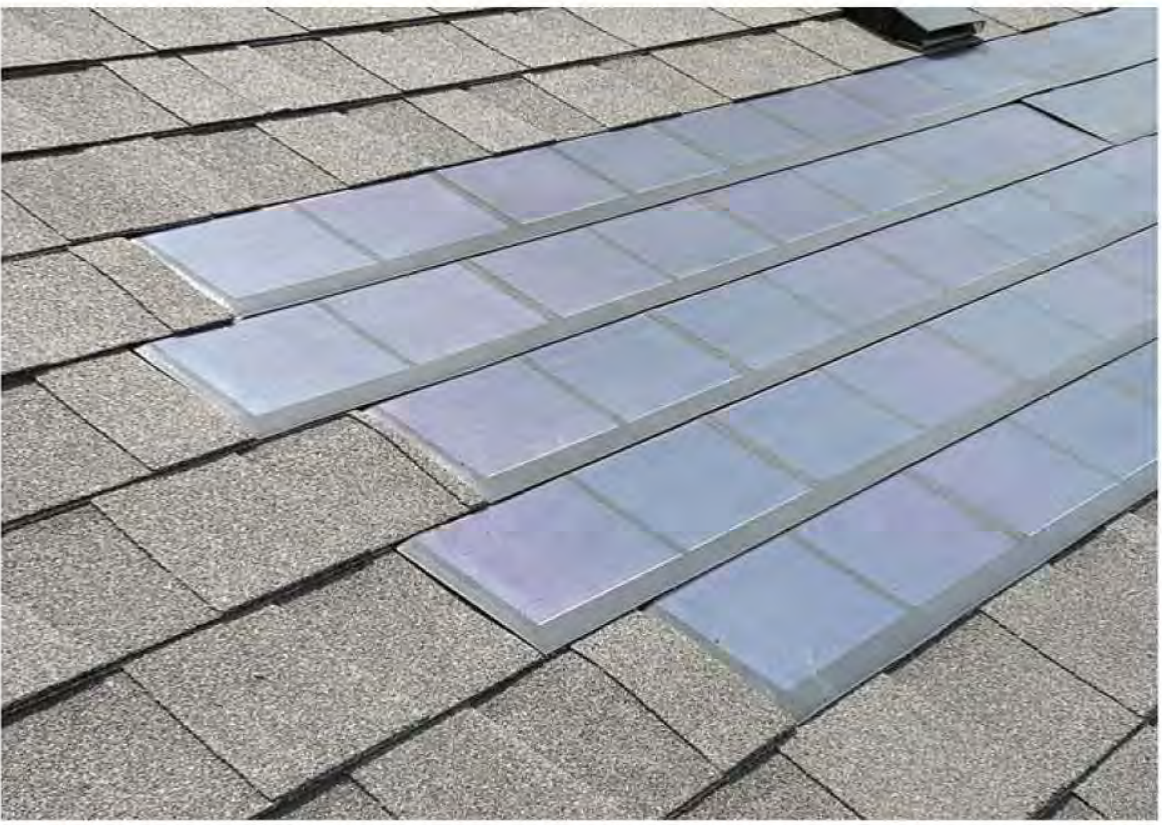

PowerShingle applied on an asphalt shingle roof, UNI-SOLAR, (c) UNI-SOLAR 

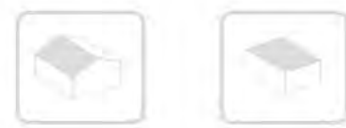

\section{Solar PV Standing Steam and}

\section{Click Roll Cap System, Rheinzink}

Ollenhauerstrasse 101, Berlin, D-13403, Germany

berlin@rheinzink.de

http://www.rheinzink.de

RHEINZINK-Solar PV for standing seam uses conventional standing seam technology. UNI-SOLAR modules are fixed fullsurface and permanently on RHEINZINK panels. These may be installed without additional fasteners in proven RHIENZINKseam techniques such as the double lock and/or angled standing seam.

RHEINZINK-Solar PV for click battens uses conventional roll cap technology: UNI-SOLAR modules are installed full-surface and permanently on RHEINZINK-panels. These can be installed on roofs and facades in the proven RHEINZINK-Click roll technology without any additional fasteners.

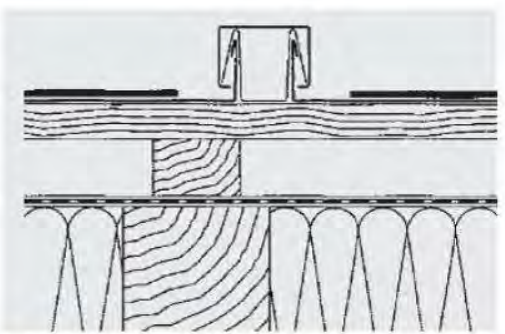

Solar PV Click Roll Cap System, (C) Rheinzink

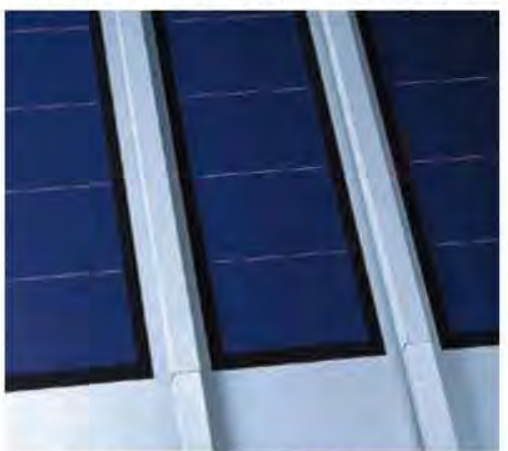

Solar PV Click Roll Cap System, ( ) Rheinzink
PV "Integrability" characteristics

\begin{tabular}{|l|c|}
\hline Multifunctional element & + \\
\hline Shape \& size flexibility & + \\
\hline Pattern choice & - \\
\hline Colour choice & - \\
\hline Jointing/ frame & + \\
\hline Availability of dummies & - \\
\hline Complete construction system & + \\
\hline
\end{tabular}

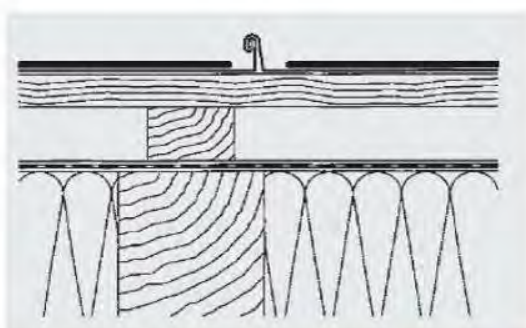

Solar PV Standing Seam System, (C Rheinzink

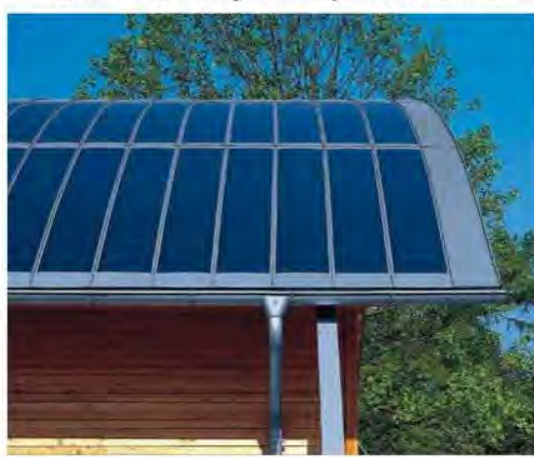

Solar PV Standing Seam System on a curved roof

C) Rheinzink 

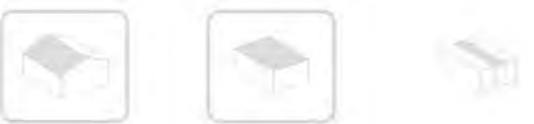

\section{XIMARCEGAGLIA Marcegaglia, Brollo solar}

Via Bresciani 16, 46040 Gazoldo Ippoliti, Mantova, Italy solar@marcegaglia.com www.marcegaglia.com

The Brollo solar panel is a part of a fully integrated roofing system. This system can be used for industrial roofs in a common and very fast way. The Photovoltaic module is glued directly on a corrugated metal sandwich. Due to the adopted thin film technology, it exhibits better performance compared to that of crystalline silicon because of its higher sensitivity to diffuse radiation, its better tolerance to shadow and single cell faults and its lower sensitivity to high temperatures. The module can be easily handled due to his lower weight compared to other systems.

The installation and the maintenance are easy and results to lower costs. Different module dimension are possible toghether with dummies elements.

The colour of the system can be a limit because it is related to the UniSolar PV Technology. The metallic substrate allows installation on curved roofs.

PV "Integrability" characteristics

\begin{tabular}{|l|c|}
\hline Multifunctional element & + \\
\hline Shape \& size flexibility & + \\
\hline Pattern choice & - \\
\hline Colour choice & - \\
\hline Jointing/ frame & n. d. \\
\hline Availability of dummies & + \\
\hline Complete construction system & + \\
\hline
\end{tabular}
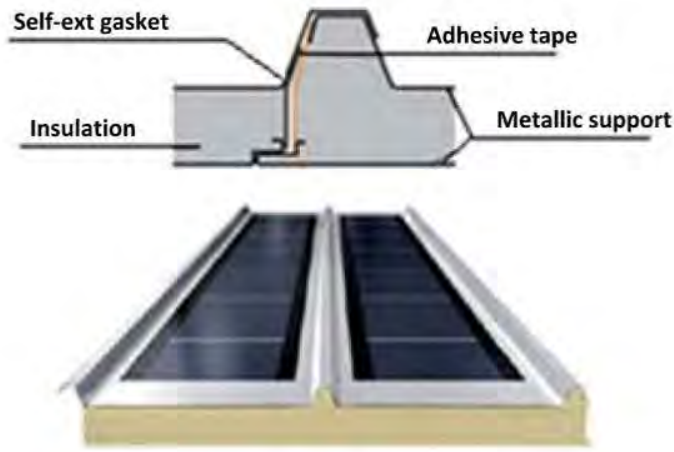

www.marcegaglia.com, (c) Marcegaglia

Brollo Solar insulated panel,

(C) Marcegaglia

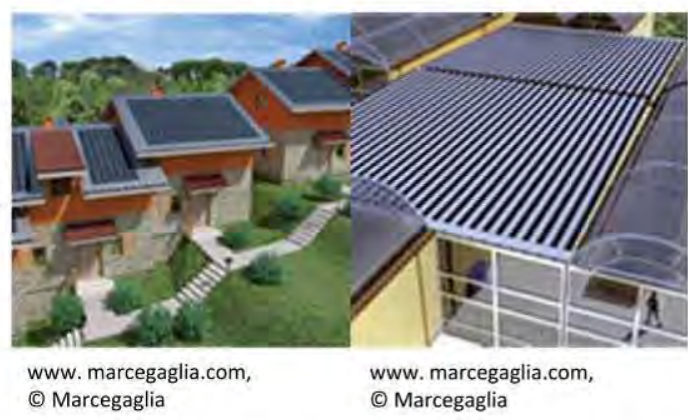



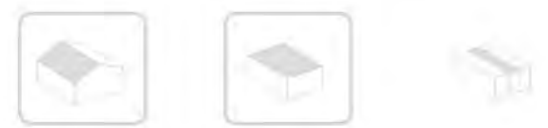

\section{flexcell VHF - Technologies, Flexcell}

Rue Edouard-Verdan 2, CH-1400 Yverdon-les-Bains,

Switzerland

info@flexcell.com

www.flexcell.com

The FLX - MO135 module is a lightweight galvanized steel plate with PV laminate on top. It is specifically adapted for trapezoidal and PVC roofing systems and it is suitable for any roof tilt and orientation. It is provided with a quick-built system which uses the existing roof as backing structure.

The FLX - TO135 is an amorphous silicon PV module laminated into a TPO (Thermo-Plastic Polylefin) roofing membrane designed for flat roof applications. It can be considered fully integrated as it uses the waterproofing layer as substrate. The system is installed as a standard waterproofing thermoplastic membranes as single or double layers system. Due to the adopted PV material (aSI) there is no colour choice, it is limited to one (as in the picture). The PV membrane can be easily installed also on curved roofs and on different substrates.

\begin{tabular}{|l|c|}
\hline \multicolumn{2}{|c|}{ PV "Integrability" characteristics } \\
\hline Multifunctional element & + \\
\hline Shape \& size flexibility & + \\
\hline Pattern choice & - \\
\hline Colour choice & - \\
\hline Jointing/ frame & n. d. \\
\hline Availability of dummies & + \\
\hline Complete construction system & + \\
\hline
\end{tabular}

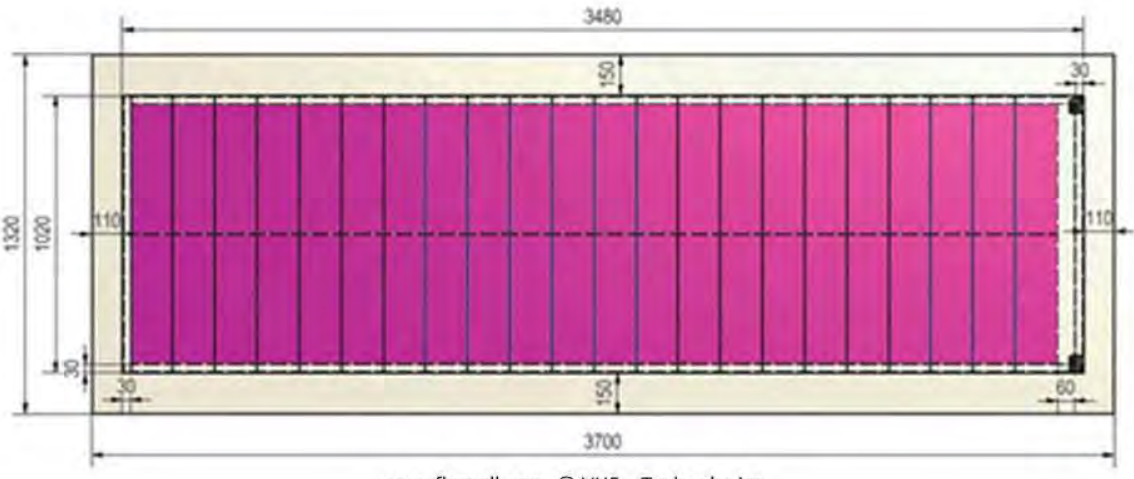

www.flexcell.com, (c) VHF-Technologies

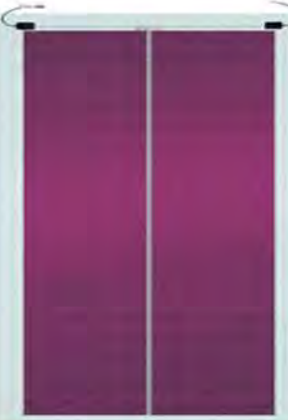

FLX-MO module, (c) VHF - Technologies

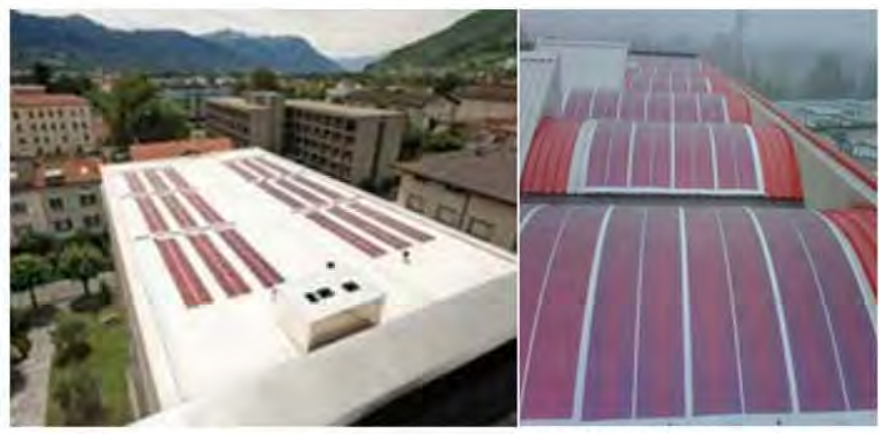

FLX-TO Installation - Bellinzona (CH), (C) VHF - Technologies
FLX-MO Installation

Vigonovo di Fontanafredda (I) (c) VHF - Technologies 


\section{БСнЁсо SCC 60 Ventilated cladding}

Schüco International KG

Karolinenstraße 1-15, 33609 Bielefeld Germany

info@schueco.com

http://www.schueco.com

\section{The Schüco ventilated façade SCC 60 (Solar Cladding}

Construction) integrates Schüco ProSol TF modules. The thin

film technology PV is applicable on opaque façade surfaces in new builds and renovation projects.

The favourable features of the thin film technology is high production in diffuse light and the module's low sensitivity to partial shading and high outside temperatures. As a result, the highest possible specific system outputs are achieved per installed kWp.

The Schüco SCC 60 cold façade performs several functions simultaneously, providing very good insulation values as well as additional solar energy.

PV "Integrability" characteristics

\begin{tabular}{|l|c|}
\hline Multifunctional element & + \\
\hline Shape \& size flexibility & + \\
\hline Pattern choice & + \\
\hline Colour choice & + \\
\hline Jointing/ frame & + \\
\hline Availability of dummies & + \\
\hline Complete construction system & + \\
\hline
\end{tabular}
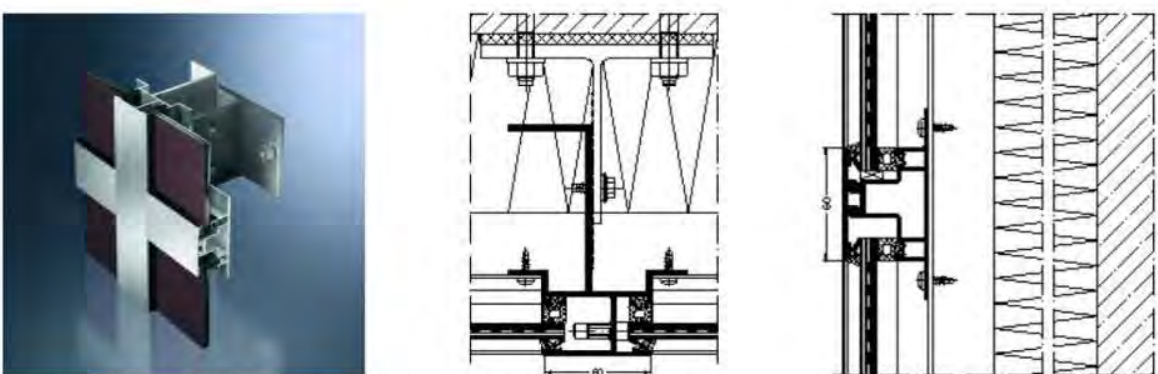

Façade SCC 60 with Schüco façade module ProSol TF
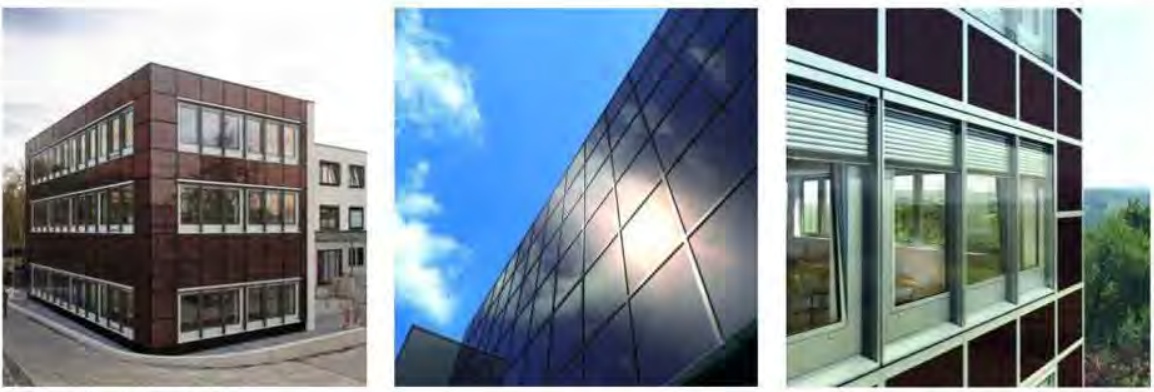

Franhofer Institute, Germany 


\section{SСHÜCO ProSol TF}

Schüco International KG

Karolinenstraße 1-15, 33609 Bielefeld Germany

info@schueco.com

http://www.schueco.com

As thermal insulating glass in Windows and Curtain Wall façades, Schüco ProSol TF takes on the central functions of the building envelope, bringing together solar shading, weather resistance, sound reduction, thermal insulation and energy generation in a single building component. ProSol TF is suitable for use as semi-transparent thermal insulating glass or opaque glazing in the spandrel area. The amorphous thin-film technology makes complex, homogenous surfaces possible.

Degrees of transparency up to $30 \%$ can be achieved by

means of laser cutting, thereby creating a close visual connection with the surroundings. Laser cutting can also be used to generate patterns and textures.

PV "Integrability" characteristics
\begin{tabular}{|l|c|}
\hline Multifunctional element & + \\
\hline Shape \& size flexibility & + \\
\hline Pattern choice & + \\
\hline Colour choice & + \\
\hline Jointing/ frame & + \\
\hline Availability of dummies & + \\
\hline Complete construction system & + \\
\hline
\end{tabular}
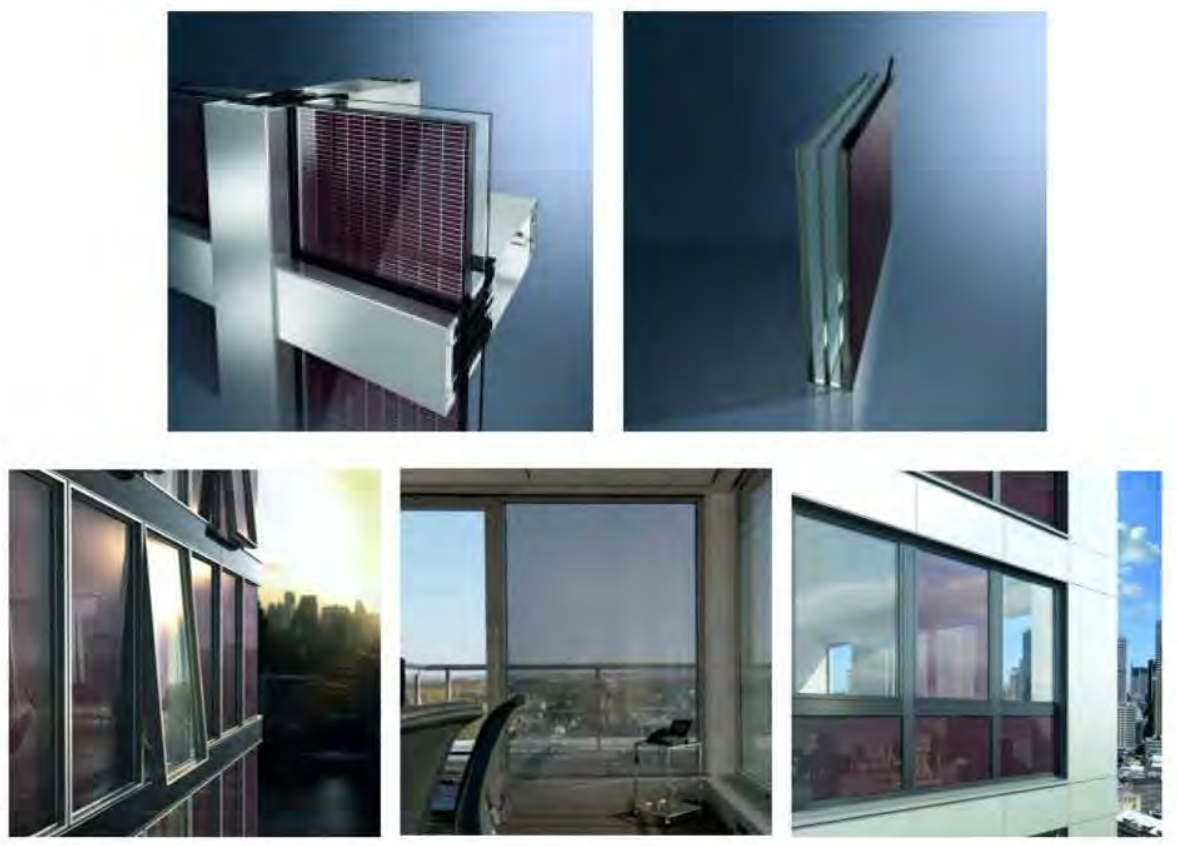

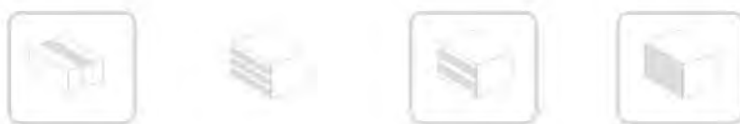

\section{SCHOIT}

\section{Schott AG, ASI THRU, ASI OPAK}

Hüttenstrasse 1, 31073, Grünenplan, Germany

Info.architecture@schott.com

www.schott.com/architecture

$\mathrm{ASI}^{\circ}$ Glass elements can fulfill many requirements of modern building envelopes and are available in various design options. The system can be used for many applications. They can be semi-transparent (THRU) or non-transparent (OPAK). The elements are available as both laminated glass and as double glazing unit, which can be combined with many types of conventional framing systems.

Static load requirements can be met by changing the type and thickness of the glass panes. The $\mathrm{ASI}^{*}$ solar cells are encapsulated with laminated foils. In addition to a large number of standard types and sizes, customised solutions can also be provided.

Furthermore, they contribute to the minimisation of heat gain in summer (reduction of the total heat gain coefficient) and, thermal loss in winter, when included in high performance windows. Different foils as coating can be used in order to change the colour of the front or of the back glass. Glare is still an issue.

\begin{tabular}{|l|c|}
\hline \multicolumn{2}{|c|}{ PV "Integrability" characteristics } \\
\hline Multifunctional element & ++ \\
\hline Shape \& size flexibility & + \\
\hline Pattern choice & + \\
\hline Colour choice & + \\
\hline Jointing/ frame & + \\
\hline Availability of dummies & + \\
\hline Complete construction system & + \\
\hline
\end{tabular}

\section{Module options with $\mathrm{ASI}^{\odot}$ Glass}
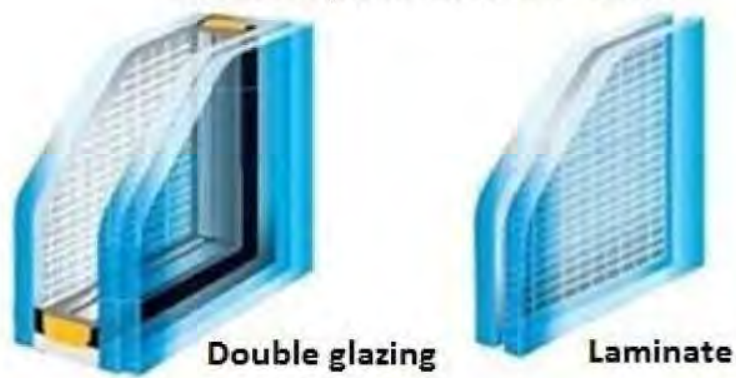

www.schott.com, (c) Schott AG

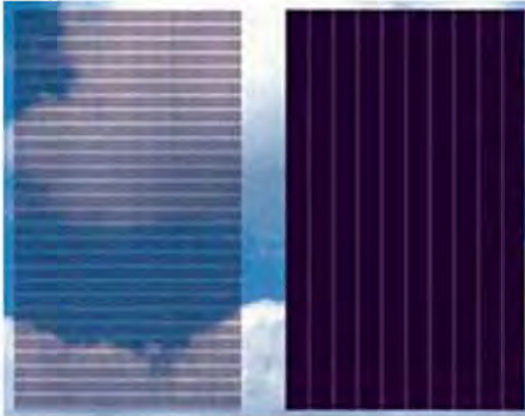

ASI-THRU॰ \& ASI-OPAK ${ }^{*}$ modules, (c) Schott AG

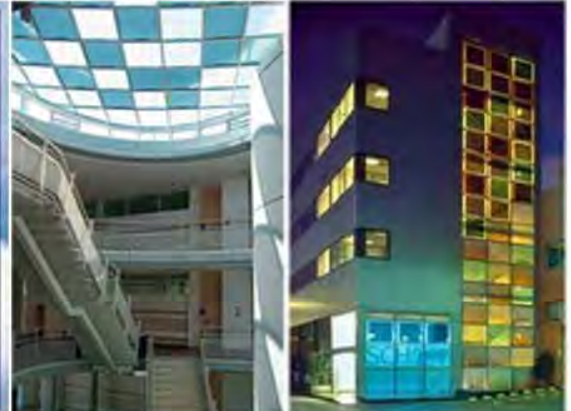

Solar facade SCHOTT Ibérica Barelona 2005 (ES),
Double roof glazing: primary school (c) Schott AG 

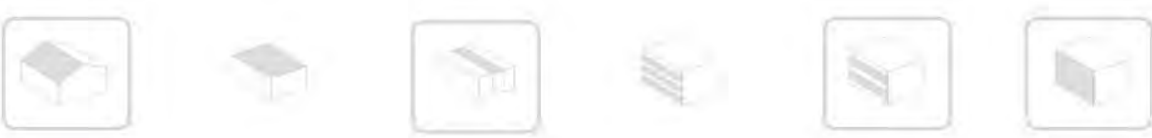

\section{WÜrTh SOLAR GeneCIS}

Würth Solar

Alfred-Leikam-Straße 25, 74523 Schwäbisch-Hall, Germany wuerth-solar@we-online.de

www.wuerth-solar.de

They are multilayered CIS (Copper-Indium-Diselenide) modules which are suitable for all fields of application and sizes of solar energy systems.

They are characterized by a homogeneous black module surface. Due to their appearance, the modules are suitable for incorporating into architectural designs.

These modules can be provided in a wide range of sizes, form and power output.

They are also delivered in glass/glass compound with or without frame.

Differently patterned, semi-transparent modules encourage the imagination of architects. In combination with colored backgrounds and/or printed shaping, the creative integration becomes possible up to the moment the material seems to disappear optically like a chameleon.

\section{PV "Integrability" characteristics}

\begin{tabular}{|l|c|}
\hline Multifunctional element & + \\
\hline Shape \& size flexibility & + \\
\hline Pattern choice & + \\
\hline Colour choice & + \\
\hline Jointing/ frame & + \\
\hline Availability of dummies & + \\
\hline Complete construction system & + \\
\hline
\end{tabular}

Different patterns and different colours are available
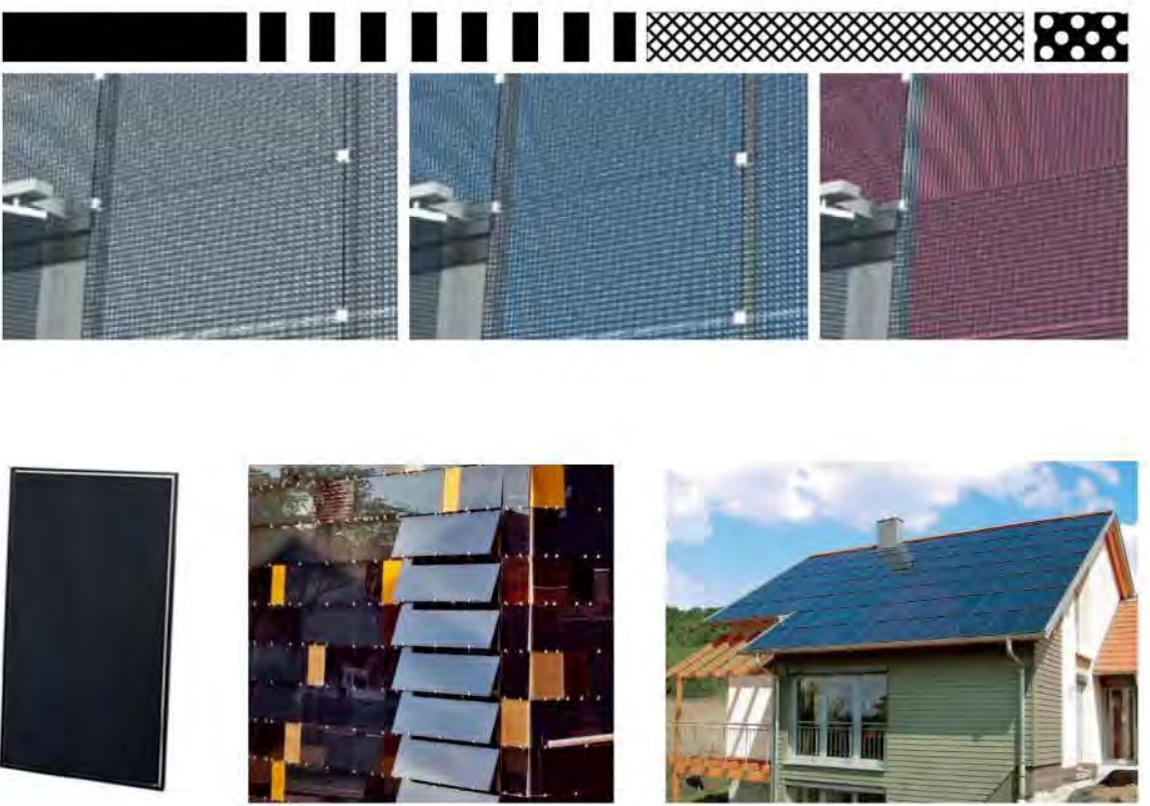


\section{5oltecture Corium PV façade solution, Soltecture Solartechnik}

Groß-Berliner Damm, 149 - 12487 Berlin (D)

info@infosulfurcell.de

www.sulfurcell.com

The Soltecture modules are based on the system used for facade cassette cladding and the PV module is applied through an adhesive technology, without use of clamping brackets or edge frames.

The modules are conceived as multifunctional elements, since they produce electrical energy as well as they protect from rain and from moisture penetrations as external building envelope. Behind the cassette system, there is a ventilation channel which contribute to cool the PV modules and prevents interstitial condensation as well.

The PV modules have standard dimensions but other sizes are available on request, as the dummy cassettes.

The modules are proposed for façade integration of residential, industrial and commercial buildings, forming a homogenous glass surface.

PV "Integrability" characteristics

\begin{tabular}{|l|c|}
\hline Multifunctional element & + \\
\hline Shape \& size flexibility & + \\
\hline Pattern choice & - \\
\hline Colour choice & - \\
\hline Jointing/ frame & + \\
\hline Availability of dummies & + \\
\hline Complete construction system & + \\
\hline
\end{tabular}

Module standard size: $1250 \mathrm{~mm} \times 650 \mathrm{~mm}$. Weight: $20 \mathrm{~kg}$ Thickness: $85 \mathrm{~mm}$ 

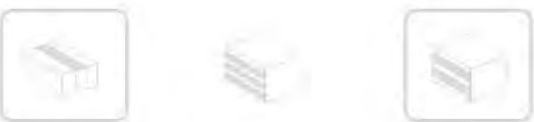

\section{KYeSEMI Sphelar®, Kyosemi}

949-2 Ebisu-cho, Fushimi-ku, Kyoto-shi, 612-8201 Japan

info@kyosemi.co.jp

www.kyosemi.co.jp

PV "Integrability" characteristics

Sphelar ${ }^{\star}$ are spherical solar cells produced by Kyosem Corporation (each cell measures $1-2 \mathrm{~mm}$ ) and their main characteristic is that both sides generate electricity wherever located is the light source.

The cells can be integrated in different low power applications, but also in see-through solar modules, which are custom-made. The transparency of the modules can vary from 20 to $80 \%$ and varied shapes are available from curved surface to pliable sheet. The product needs further development, in order to have some standardized products for building integration.
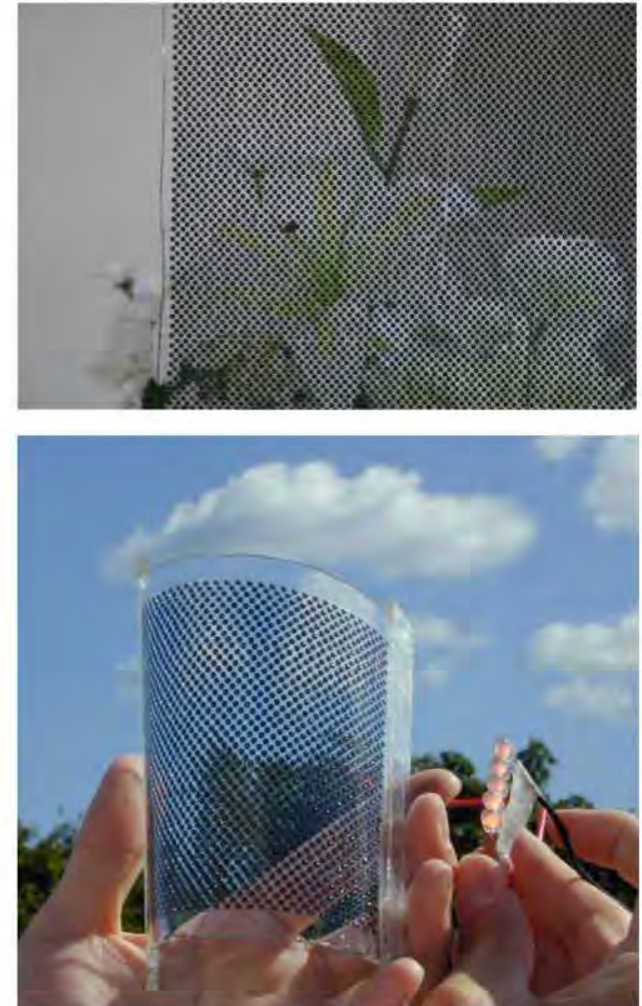

Sphelar spherical solar cells, (C) Kyosemi

\begin{tabular}{|l|c|}
\hline Multifunctional element & + \\
\hline Shape \& size flexibility & + \\
\hline Pattern choice & + \\
\hline Colour choice & - \\
\hline Jointing/ frame & + \\
\hline Availability of dummies & - \\
\hline Complete construction system & - \\
\hline
\end{tabular}




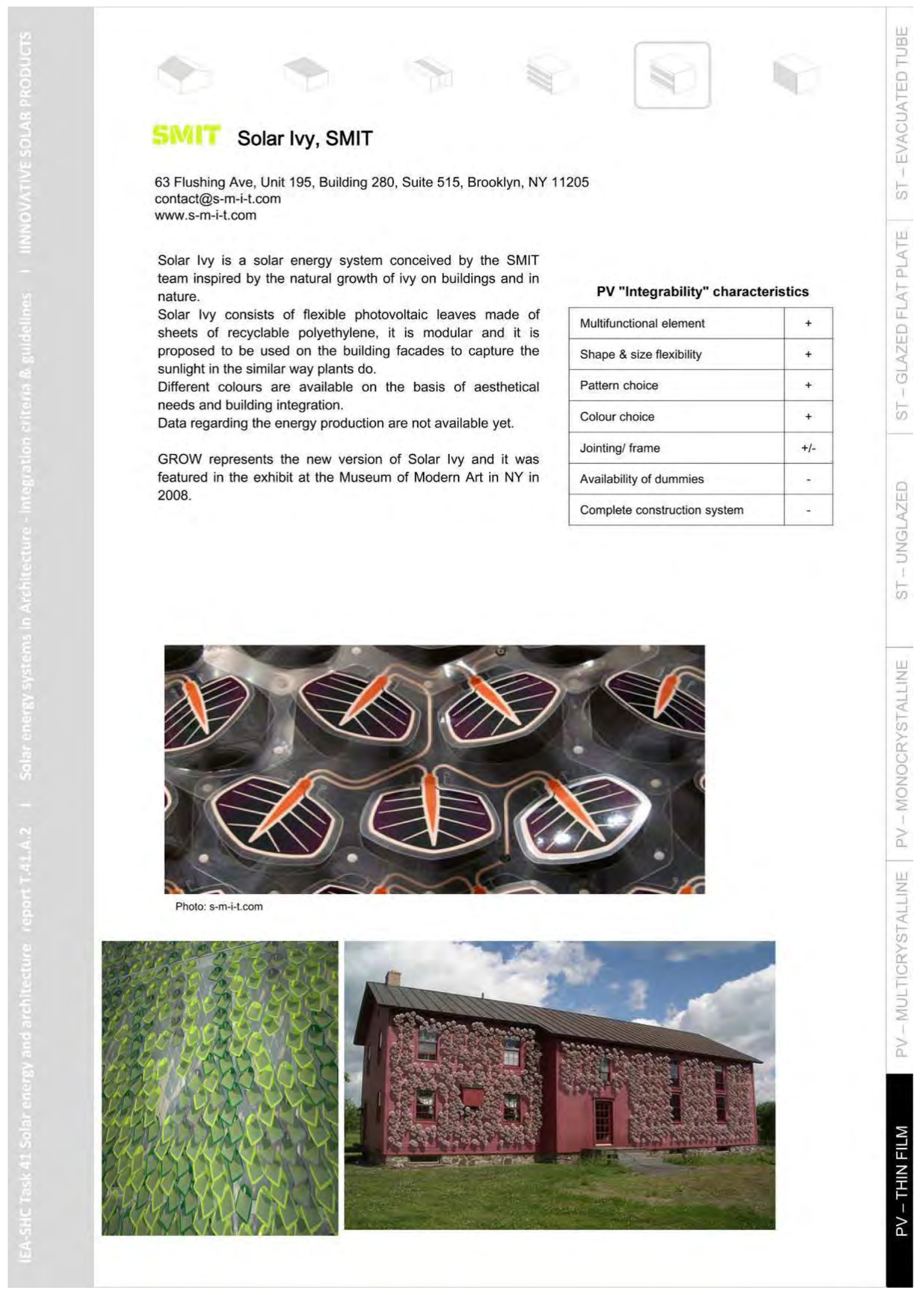




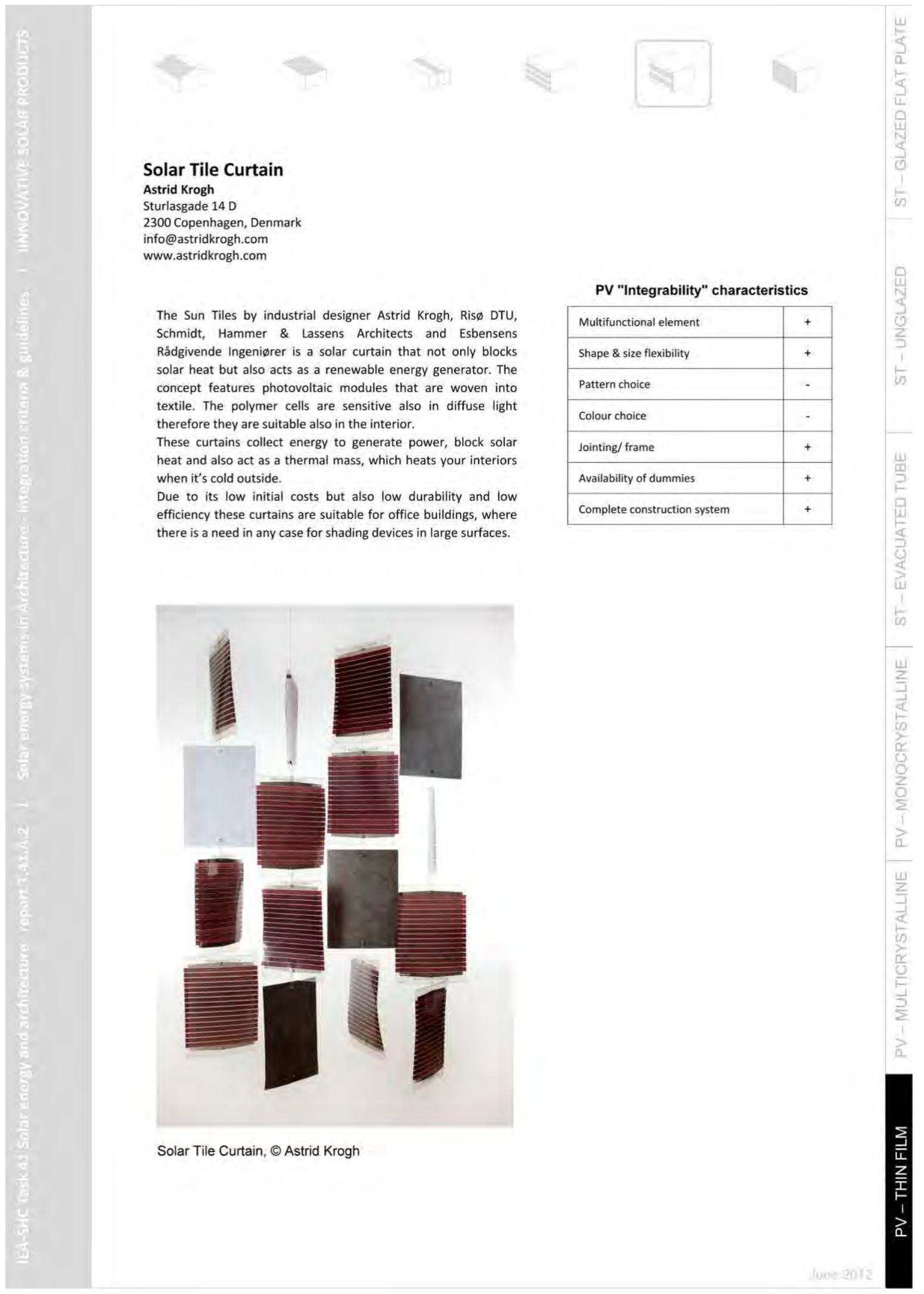



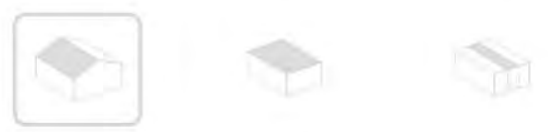

\section{Systaic AG}

www.systaic.com

Flat surface completely covered with glass, covered frame glass corners protected by PU.

Capacity transmitted in frames, no loose cables.

Louvre window able to be integrated in the roof grid, frames covered with glass like the energy units.

Folding shutter, expandable up to three rows horizontally; electrically operable; installable for completion of balconies,

roof terraces, etc.

Dimensions: $1.045 \times 1.045 \times 40 \mathrm{~mm}$

Weigh: $18 \mathrm{~kg}$

\begin{tabular}{|l|c|}
\hline \multicolumn{2}{|c|}{ PV "Integrability" characteristics } \\
\hline Multifunctional element & + \\
\hline Shape \& size flexibility & - \\
\hline Pattern choice & - \\
\hline Colour choice & - \\
\hline Jointing/ frame & + \\
\hline Availability of dummies & + \\
\hline Complete construction system & + \\
\hline
\end{tabular}
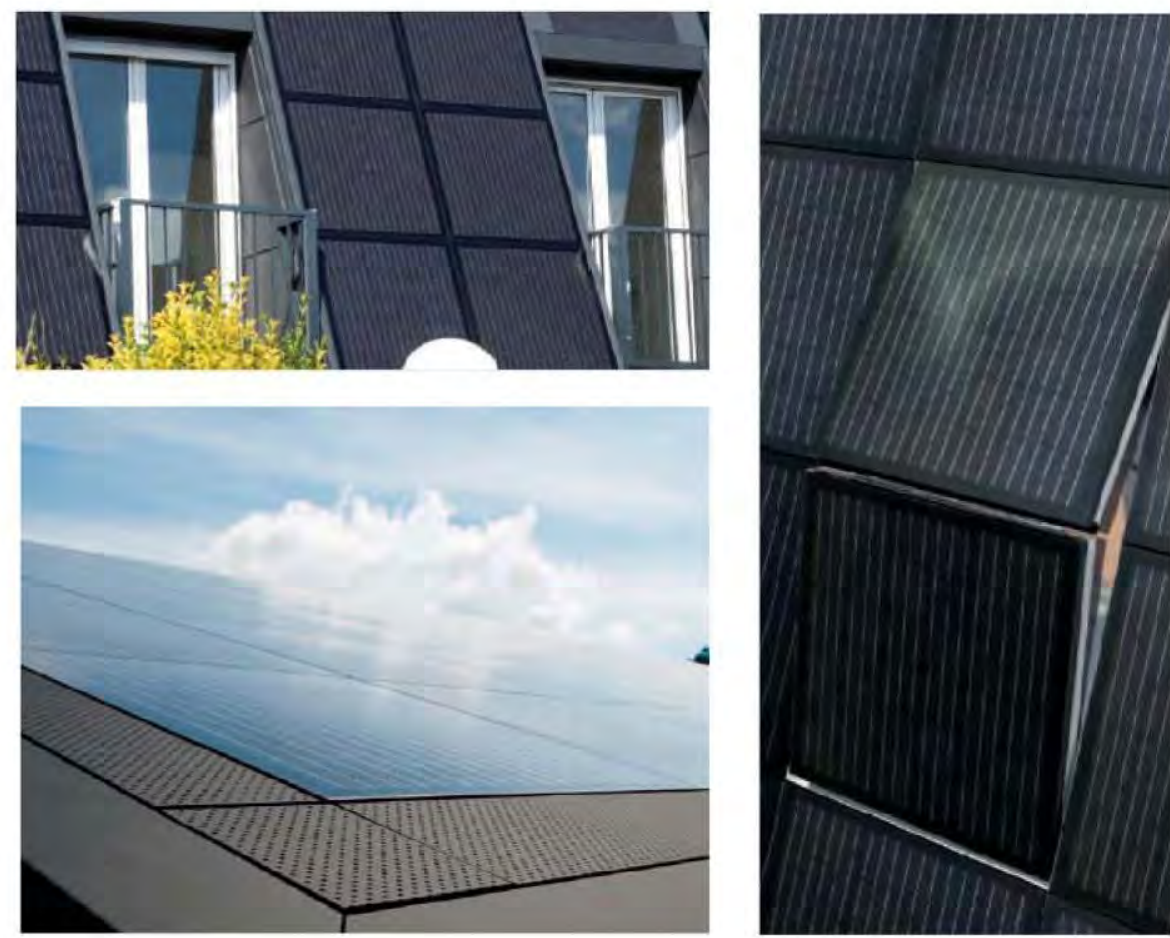


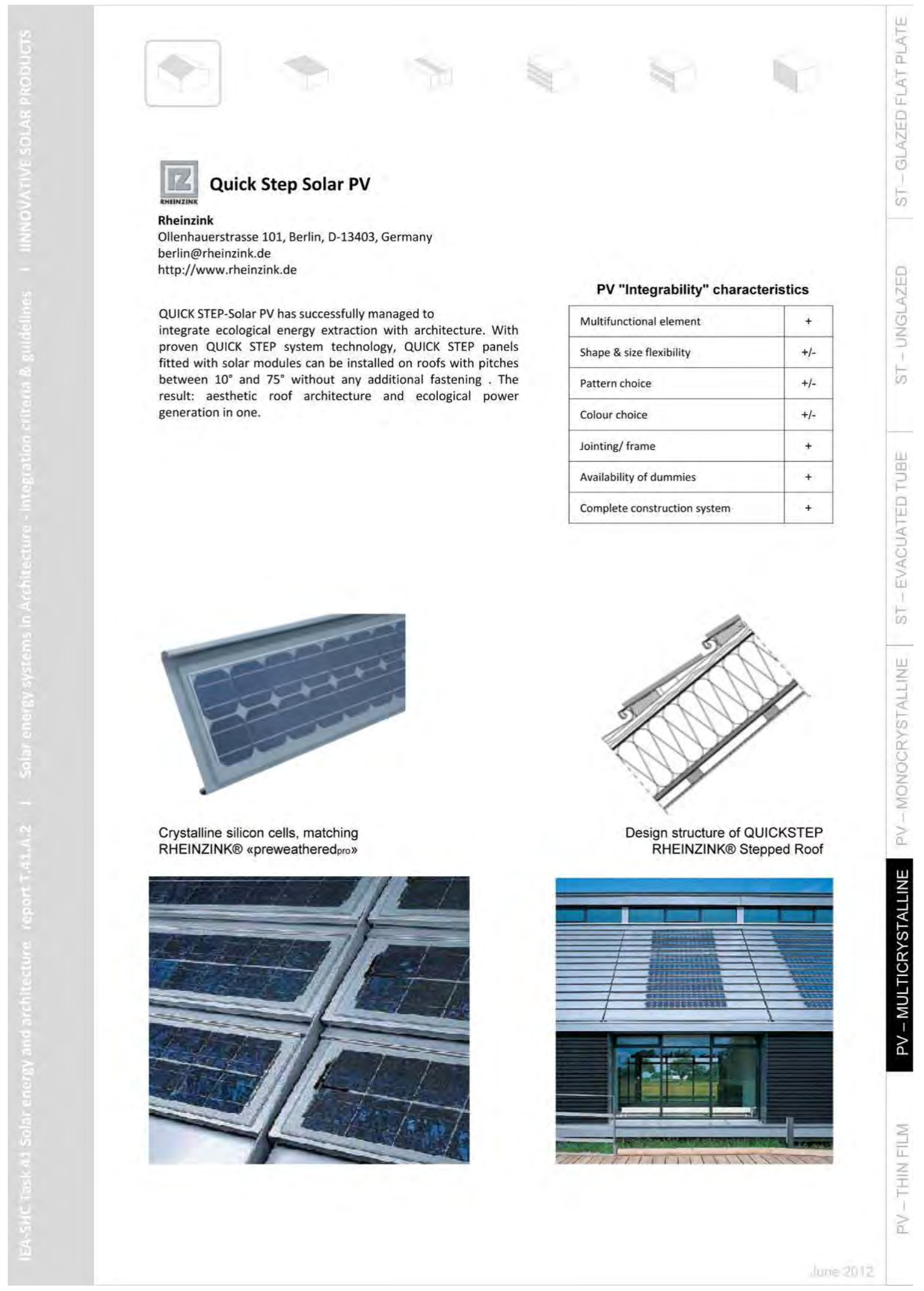




\section{CONCLUSIONS}

Building integrated photovoltaics is a present technology. The reason why it is still not commonly used by architects and planners in their projects is difficult to comprehend and to resume in a clear way. In this document of the IEA SHC Task 41 Solar Energy and Architecture, the authors tried to address the PV module manufacturers some guidelines in order to produce cost-effective and attractive PV modules for building integration and to increase the awareness of architects on this technology.

One of the main barriers that were highlighted is the lack of European and international standards for BIPV elements, which merge the IEC (low voltage directive) and CENELEC (electrotechnical standardization body) needs with the CPD (construction product directive) directives. Nowadays each country has its own national legislations (Germany: Normentwurf E DIN VDE 0126-21, Photovoltaik im Bauwesen; the Netherlands: NEN NVN 7250:2007 Solar Energy Systems - Integration In Roofs And Facades - Building Aspects), which regulate the use of the photovoltaic module as a building component. A lack of information of standards at the international level can also be found when we speak about feed-in-tariffs and subsidies for PV modules, both for building integration and ground mounted installations. This problem leads to very different national markets with different implementations of BIPV products. This is the case of Italy, France (and partially in Switzerland [6.1]) where the feed-in-tariffs are very convenient for BIPV installations (as the requirements are related to the use of special PV products for building integration) as opposed to the ground mounted or added PV systems. But each country has different criteria, meaning that what is considered as BIPV in Italy can be differently interpreted in France or in Switzerland with an important influence on the mark potential of the product in the different countries, depending on the brand potential of the product in the different countries. This problem will be solved only when BiPV system will became more economical feasible and the grid parity is reached. In this case national PV incentives will not be needed anymore.

On the other hand, the international survey conducted within the framework of IEA SHC Task 41 showed that architects found the availability of suitable products for building integration one of the main strategies to enhance the use of PV modules in the everyday architectural practice [6.2]. Building integrated photovoltaic modules should not only be developed as added technical elements but as building components that have to fulfil the functional, constructional and formal requirements of the building components they replace. This document focused on these requirements in order to highlight the architects' needs of a widespread use of photovoltaics in the built environment. 


\section{REFERENCES}

[0.1] M.C., Munari Probst, and C. Roecker, Towards an improved architectural quality of building integrated solar thermal systems (BIST). Solar Energy, 81 (9), 2007 pp.1104-1116.

[0.2] D.F. Montoro et al, Barriers for the introduction of Photovoltaics in the building sector. Sunrise Project, 2008. [online] Available at: http://www.epia.org/uploads/media/Study_on_Barriers_01.pdf [Accessed 10 October 2010]

[2.1] MC Munari Probst, $C$ Roecker, Architectural integration and design of solar thermal systems, PPUR -Routledge, Taylor\&Francis, 2011

Klaudia Farkas (NTNU, Norway), Miljana Horvat (Ryerson University, Canada) T.41.A.1: Building Integration of Solar Thermal and Photovoltaics - Barriers, Needs and Strategies mai 2012

I. Bergmann "Facade integration of solar thermal collectors - A new opportunity for planners and architects", in Renewable Energy World, June 2002.

A.G Hestnes, "Building integration of solar energy systems", in Solar Energy, 67 (4-6), 181-187, 2000.

Munari Probst MC. Architectural integration and design of solar thermal systems PhD thesis EPFL n. 4258, 2008.

MC.Munari Probst, C.Roecker, A. Schueler, Architectural integration of solar thermal collectors: results of an European survey", in Proceedings ISES 2005, Orlando, Florida, 2005.

F. Frontini, T. Friesen, Building Integrated Photovoltaic: challenges for manufacturers and designers, in Proceeding Energy Forum 2012, Brixen. 2012

CLC/TC 82, Solar photovoltaic energy systems, http://www.cenelec.eu/dyn/www/f?p=104:7:3621654491259393::::FSP_ORG_ID: 989

[3.2] K. Farkas, The Perception of Formal and Symbolic Aesthetics of Photovoltaics. Proceedings of ISES Solar World Congress 2011, 2011, ISBN 9783981465907

[3.3] K. Farkas, I. Andresen, A.G. Hestnes, Architectural Integration of Photovoltaic Cells, Overview of materials and products from an architectural point of view, SASBE 2009, The Hague, June 2009

[3.4] K. Farkas, Formal aspects of product development of photovoltaics recommendations for manufacturers, EuroSun 2012, Zagreb, September 2012

[3.5] M.C. Munari Probst; C. Roecker, Towards an improved architectural quality of building integrated solar thermal systems (BIST). Solar Energy, 81 (9) (2007), pp.1104-1116.

[3.6] A. Scognamiglio et Al., Aesthetical appeal of BIPV or electrical performance, Proceedings PV in Europe-From PV technology to energy solutions, 2002, pp. 1109-1112, ISBN 3-936338-13-2 ISBN 88-900971-3-2.;

[3.7] A.G. Lien, Visual studies of transparent PV - elements, Eurosun 2000, Copenhagen, June 2000 
[3.8]

[4..10] A. Giovanardi, P. Baldracchi, R. Lollini. New test bench for the performance

assessment of solar envelope systems, in proceedings of the 5th Energy Forum Solar Building Skins, Bressanone-Italy (2010).

S. Mende, F. Frontini, J. Wienold . Comfort and building performance analysis of transparent building integrated silicon photovoltaics. In: Proceedings of Building Simulation 2011. Sydney. 2011

A. Scognamiglio et Al., Boogie-Woogie, a photovoltaic glass-glass module "dancing" with the building, Proceedings of the 21st EUPVSEC, 2006, pp. 28532856, ISBN 3-936338-20-5

R. Baum, Architectural integration of light transmissive Photovoltaic (LTPV), 26th EUPVSEC Proceedings, ISBN ISBN 3-936338-27-2, pp. 3967-3976.

R. Baum, Alternative solar cell patterns for light-transmissive photovoltaic panels, ISES 2011, Kassel, August 2011

F. Frontini, T. Friesen, Building Integrated Photovoltaic: challenges for manufacturers and designers, in Proceeding Energy Forum 2012, Brixen. 2012

Dr. Christoph F. Reinhart, Tutorial on the Use of Daysim Simulations for Sustainable Design, Institute for Research in Construction National Research Council Canada, Ottawa, Ont., K1A 0R6, Canada, 2006

Dr. R. Compagnon; RADIANCE: a simulation tool for daylighting systems; The Martin Centre for Architectural and Urban Studies University of Cambridge Department of Architecture

F. Frontini, T. E. Kuhn, S. Herkel, P. Strachan, G. Kokogiannakis, Implementation of a new bi-directional solar modelling method for complex façades within the ESP-r building simulation program and its application, 11th International Building Performance Simulation Association Conference and Exhibition in 2009. Glasgow.

G.W. Larson, R. Shakespeare, Rendering with Radiance : the art and science of lighting visualization, Morgan Kaufmann: San Francisco, 1998.

F. Frontini, Daylight and Solar Control in Buildings: General Evaluation and Optimization of a New Angle Selective Glazing, PhD Thesis, Politecnico di Milano, 2009, Fraunhofer Verlag, ISBN 978-3839602386

F. Frontini, T.E. Kuhn, A new angle-selective, see-through bipv façade for solar control, Eurosun Conference 2010, Graz, September 2010.

F. Frontini, E. Zambelli, G. Masera, G. Salvalai, Sustainable Smart-ECO Buildings: an integrated energy and architecture design (IEAD) process to optimize the design of the new buildings for the Technical University in Lecco, Italy, REHVA world congress Clima 2010. Antalya. 2010

F. Frontini, T. E. Kuhn, Eine neue Methode für die Modellierung des Transmissiongrad der Solarenergie von komplexen Fassaden mit dem Esp-r Gebäude Simulation Programm und seinen Anwendungen, 20Symposium Thermische Solarenergie, Mag. 2010

Cost-Effective newsletter WP3, available online at: http://www.cost-effectiverenewables.eu/publications.php?type=info 
T. Schoen, D. Prasad, D. Ruoss, P. Eiffert, H. Sørensen, Task 7 of the IEA PV power systems program - achievements and outlook, Proceedings of the 17th European Photovoltaic Solar Conference, (2001)

[4..12] L. Maturi, R. Lollini, P. Baldracchi, W. Sparber. Building skin as electricity source: the prototype of a wooden BIPV façade component

[4..13] Energy-efficient buildings ppp - Multi-annual roadmap and longer term strategyprepared by the Ad-hoc Industrial Advisory Group, European Commission

[6.1] More information about Swiss Feed in Tariff situation can be found here: http://www.stiftung-kev.ch/it/incentivi.html

[6.2 ] Farkas, K., Munari Probst, M.C., Horvat, M., Barriers and Needs for Building Integration of Solar Thermal and Photovoltaics, In the Proceedings of EuroSun 2010, Graz, Sept. 2010 
ANNEX 


\section{SHC \\ SOLAR HEATING \& COOLING PROGRAMME} INTERNATIONAL ENERGY AGENCY

\section{IEA SOLAR HEATING AND COOLING PROGRAMME}

The Solar Heating and Cooling Programme was founded in 1977 as one of the first multilateral technology initiatives ("Implementing Agreements") of the International Energy Agency. Its mission is to "advance international collaborative efforts for solar energy to reach the goal set in the vision of contributing $50 \%$ of the low temperature heating and cooling demand by 2030."

Its primary area of work is the facilitation of research, development \& demonstration (RD\&D) in the field of solar thermal energy and solar buildings. To this end international research projects (so called "Tasks") are sponsored by the IEA SHC members.

A total of 49 such projects have been initiated to-date, 39 of which have been completed already. The current projects are:

- Solar Energy in Urban Planning (Task 51)

- Advanced Lighting Solutions for Retrofitting Buildings (Task 50)

- Solar Heat Integration in Industrial Processes (Task 49)

- Quality Assurance and Support Measures for Solar Cooling Systems (Task 48)

- Solar Renovation of Non-Residential Buildings (Task 47)

- Solar Resource Assessment and Forecasting (Task 46)

- $\quad$ Large Scale Solar Heating and Cooling Systems (Task 45)

- Solar and Heat Pump Systems (Task 44)

- Solar Rating and Certification Procedures (Task 43)

- Compact Thermal Energy Storage (Task 42)

- Net Zero Energy Solar Buildings (Task 40)

- Polymeric Materials for Solar Thermal Applications (Task 39)

In addition to the project work, a number of special activities - Memorandum of Understanding with solar thermal trade organizations, statistics collection and analysis, conferences and workshops - have been undertaken. An annual international conference on solar heating and cooling for buildings and industry was launched in 2012. Its first edition, SHC2012, was held in San Francisco. 
Current members of the IEA SHC

$\begin{array}{lll}\text { Australia } & \text { Germany } & \text { Portugal } \\ \text { Austria } & \text { Finland } & \text { Singapore } \\ \text { Belgium } & \text { France } & \text { South Africa } \\ \text { China } & \text { Italy } & \text { Spain } \\ \text { Canada } & \text { Mexico } & \text { Sweden } \\ \text { Denmark } & \text { Netherlands } & \text { Switzerland } \\ \text { European Commission } & \text { Norway } & \text { United States }\end{array}$

Further information:

For up to date information on the IEA SHC work, including many free publications, please visit www.iea-shc.org 